\title{
Immunocytochemical Mapping of 1B236, A Brain-specific Neuronal Polypeptide Deduced from the Sequence of a Cloned mRNA ${ }^{1}$
}

\author{
F. E. BLOOM, ${ }^{2}$ E. L. F. BATTENBERG, R. J. MILNER, AND J. G. SUTCLIFFE*
}

Division of Preclinical Neuroscience and Endocrinology and *Department of Molecular Biology, Research Institute of the Scripps Clinic, La Jolla, California 92037

\begin{abstract}
The 318-amino acid, carboxy-terminal sequence of the putative brain-specific polypeptide 18236 was deduced from the nucleotide sequence of its cloned brain-specific mRNA. Antisera raised against selected synthetic peptide fragments of this protein were used to map the cellular location of the presumptive gene product in the brains of normal or colchicine-pretreated adult rats. Antisera directed against any of three C-terminally located, but nonoverlapping, nonhomologous, synthetic peptide segments (P5, P6, or P7) produced virtually identical maps of intensely immunoreactive neuropil staining. The immunoreactivity was distributed heterogeneously and was most pronounced within olfactory, somatosensory, and limbic systems, and was more modest in certain motor and auditory structures. In colchicine-pretreated rats, large, multipolar perikarya were observed within the amygdala, caudate-putamen, cingulate, parietal, and piriform cortices, as well as in particular diencephalic and pontine nuclei. Smaller immunoreactive neurons with more limited dendritic extensions were observed in the olfactory bulb, the cerebellar cortex, and the dorsal horn and intermediolateral cell columns of the spinal cord. No immunoreactivity was observed in visceral structures innervated by the autonomic nervous system or in non-neural tissues. In addition to the virtually superimposable maps produced by antisera to all three synthetic fragments selected from the C-terminus of 1B236, some uniquely reactive sites were seen. Antisera to the most $\mathrm{N}$-terminal of the three synthetic immunogens (P5) were reactive with neurons of the medial trapezoid nucleus and in nerve terminals surrounding the deep cerebellar nuclei. Antisera against the most $\mathrm{C}$-terminal synthetic immunogen (P7) were reactive with neurons of the paraventricular and supraoptic hypothalamic nuclei. These data demonstrate that the 1B236 protein is located within selected neuronal elements within functionally related cellular circuits established more formally by other methods. Our data show that protein 1B236-immunoreactive cells share at least the expression of this protein and suggest that these cells may also be related epigenetically or evolutionarily. These data, together with other subcellular, ultrastructural, and electro-
\end{abstract}

Received September 7, 1984; Revised November 19, 1984;

Accepted November 27, 1984

\footnotetext{
1 We thank Mary Kiel for immune serum preparation, Nancy Callahan for manuscript preparation, Jamie Simon for artwork, and Dr. John Morrison for critical discussions of anatomic details. This work was supported in part by National institutes of Health Grants GM 32355 and NS 20728, and by the McNeil Laboratories.

${ }^{2}$ To whom correspondence should be addressed
}

physiological properties of 1B236, suggest that this protein could be considered as a prohormone capable of yielding several final candidate transmitter products.

Attempts to define the specific properties of the nervous system have generally begun with comparative analysis of its chemical or functional differences with cells of other organ systems. Likewise, attempts to clarify the uniquely complex structural organization of the brain wcre first approached through empirically derived cell staining methods supplemented later by more powerful and sensitive circuit tracing methodologies. During the past decade, anatomic studies have been powerfully extended by immunocytochemical probes to identify products known or inferred to be produced by neurons or glia. However, most neurotransmitter substances and their related synthetic or catabolic enzymes and receptors are not exclusive to the nervous system, being detected also in endocrine and exocrine tissues. Thus, relatively few brain-specific or neuronspecific molecules have been detected as yet (Barnstable, 1980 Cohen and Selvendran, 1981; Villiamy et al., 1981; Eng, 1982; Moore, 1982; Sternberger et al., 1982; Hendry et al., 1984a, b). Most of these (see McKay et al., 1981) emerged from analysis of monoclonal antibodies raised against brain. Of these potential nervous system-specific markers, only neuron-specific enolase has been characterized to the extent of molecular and cellular identification (Schmechel et al., 1978; Kennedy, 1982; Schachner, 1982; Thompson et al., 1983), and this antigen is also found in non-neural endocrine tissues. With the exceptions of the unknown monoclonal antigens said to be limited to the rat limbic system (Levitt, 1984) and vertebrate visual system (Hendry et al., 1984a), no known neural markers identify functionally defined neuronal systems.

An alternative approach to the special, but unknown, properties of neurons, both generally and individually, is the direct analysis of the gene products expressed in brain. Analysis of the poly $(A)^{+}$ messenger RNA (mRNA) present in the adult rat brain (Bantle and Hahn, 1976; Chikaraishi, 1979; Milner and Sutcliffe, 1983) has produced the estimate that at least $60 \%$ of the mRNA population actively expressed in brain - or some 30,000 mRNAs - are specific to the brain. The "brain-specific" mRNAs (i.e., those undetectable in mRNA populations from liver or kidney) tend to be much larger and of lower individual abundance than mRNA molecules that are not brain specific (Milner and Sutcliffe, 1983). In this context, "brainspecific" is an operational definition and does not exclude the possibilities that some of these molecules may also be expressed in other tissue, particularly the peripheral nervous system or endocrine system.

We have isolated cDNA clones of several brain-specific mRNAs and determined their nucleotide sequences, thereby obtaining the amino acid sequence of the corresponding proteins by deduction from the genetic code. The presumptive gene products were then detected using polyclonal antisera raised against selected synthetic 
fragments of the deduced amino acid sequences (Sutcliffe et al., 1983). In the present study, we report the detailed neuroanatomical maps resulting from immunocytochemical studies of one such brainspecific polypeptide, 1B236. We have deduced a partial amino acid sequence, 318 residues in length from the nucleotide sequence of the cDNA clone p1B236. This clone (see Sutcliffe et al., 1983) corresponds to an mRNA 2500 nucleotides in length, present at relatively low abundance in brain $(<0.01 \%$ of the total brain mRNA), but undetectable in liver or kidney mRNA populations. The cDNA clone represents approximately two-thirds of the 1B236 mRNA sequence, and the amino acid sequence deduced from it corresponds to the carboxy-terminal half of the protein. In "Northern" blotting analyses, 1B236 mRNA is found to be unequally distributed in the adult rat brain, with an abundanice roughly following a caudalto-rostral gradient in macroregional dissections (Sutcliffe et al., 1983). Antisera raised against three fragments of the deduced amino acid sequence provided preliminary evidence of a heterogeneous cellular distribution in pontine, cerebellar, cortical, and limbic structures (Sutcliffe et al., 1983).

The detailed cytological analysis of the distribution of this polypeptide, presented here, suggests that the $1 \mathrm{~B} 236$ protein may mark sequences of connected neurons within recognized circuits of the olfactory, somatosensory, and limbic systems while having a much more limited presence in other functionally defined brain circuits, such as certain components of the auditory and motor systems. Thus, this approach can provide a sensitive and unambiguous approach to the anatomical mapping of cells that express common, but relatively rare, brain-specific gene products.

\section{Materials and Methods}

The nucleotide sequence of the p1B236 cDNA insert, with its open reading frame containing the $318 \mathrm{C}$-terminal amino acids of the $1 \mathrm{~B} 236$ protein and the positions of the synthetic peptides (P4, P5, P6, and P7) used for immunization of rabbits, is shown in Figure 1. Four rabbits were immunized with each of the synthetic peptides conjugated either to thyroglobulin or edestin as previously described (Sutcliffe et al., 1983). Sera were screened for immunoreactivity against the synthetic peptides by enzyme-linked immunosorbent assay.

Positive antisera were evaluated against brain tissues fixed according to various protocols. Controls for specificity of immunoreactivity consisted of overnight incubations of optimal working dilutions of the primary antiserum in three aliquots, to which either nothing, the peptide immunogen corresponding to that antiserum $(50 \mu \mathrm{g} / \mathrm{ml})$, or an irrelevant peptide was added. The absorbed and unabsorbed sera were then reacted on adjacent sections of the same brain, and antibody binding was detected by a two-step immunoperoxidase reaction, described below. For enhancement of perikaryal immunoreactivity, rats were anesthetized, mounted in a Kopf stereotaxic instrument, and injected intracisternally with $50 \mu \mathrm{l}$ of a $1-\mathrm{mg} / \mathrm{ml}$ solution of colchicine hydrochloride in sterile saline. Rats were then fixed by perfusion 24 or $48 \mathrm{hr}$, later, and tissues were handled as described above.

Multiple positive antisera for the three immunogen peptides were successfully raised (P5: 5858, 5750, P6: 5751, 5863; and P7: 5864). The major mapping studies were done using the sera yielding the highest working dilution and lowest "background" immunoreactivity, namely, sera from rabbits 5858,5751 , and 5864 . The immunoreactivity of each antiserum was specifically blocked following absorption by its own immunogen peptide, and all were unimpaired in immunoreactivity when exposed to either of the other two immunogen peptides at equal concentrations. None of six sera from rabbits injected with conjugates of P4 showed any positive immunoreactivity in normal or colchicine-treated rats.

With the five antisera used for in-depth analysis, optimal staining was obtained in rats fixed by transcardial perfusion with freshly depolymerized $4 \%$ paraformaldehyde in $0.15 \mathrm{M}$ sodium phosphate buffer, $\mathrm{pH} 7.4$, for $5 \mathrm{~min}$, followed by removal of the brain and immersion fixation of frontal or sagittal slabs 3 to $5 \mathrm{~mm}$ in thickness for an additional 3 to $8 \mathrm{hr}$. Tissues from approximately 48 rats were used for preliminary antiserum evaluation and specificity demonstration. Detailed mapping data were then compiled from 6 normal and 6 colchicine-pretreated rats. In some cases, $0.2 \%$ picric acid was added to the perfusate with no alteration in results. Tissue slabs for light microscopy were rinsed in graded sucrose solutions $(12,16$, and $18 \%$ in phosphate-buffered saline) and stored in $18 \%$ sucrose until sectioned by cryomicrotomy at 20 to $50 \mu \mathrm{m}$. Free-floating sections were incubated overnight at $5^{\circ} \mathrm{C}$ in dilutions of primary antisera ranging from $1: 500$ to $1: 10,000$. The primary antisera binding sites were then detected, as previously described (Bloom and Battenberg, 1983), by a two-step indirect immunoperoxidase protocol using an affinity-purified goat lgG raised against rabbit lgG and conjugated to purified horseradish peroxidase (HRP). The peroxidase activity was localized by incubation in $0.05 \%$ diaminobenzidine hydrochloride (Sigma Chemical Co.) and $0.003 \% \mathrm{H}_{2} \mathrm{O}_{2}$. All reagents contained $0.3 \%$ Triton $\mathrm{X}$-100 for light microscopic localizations.

For enhancement of the reaction product and optimal contrast with

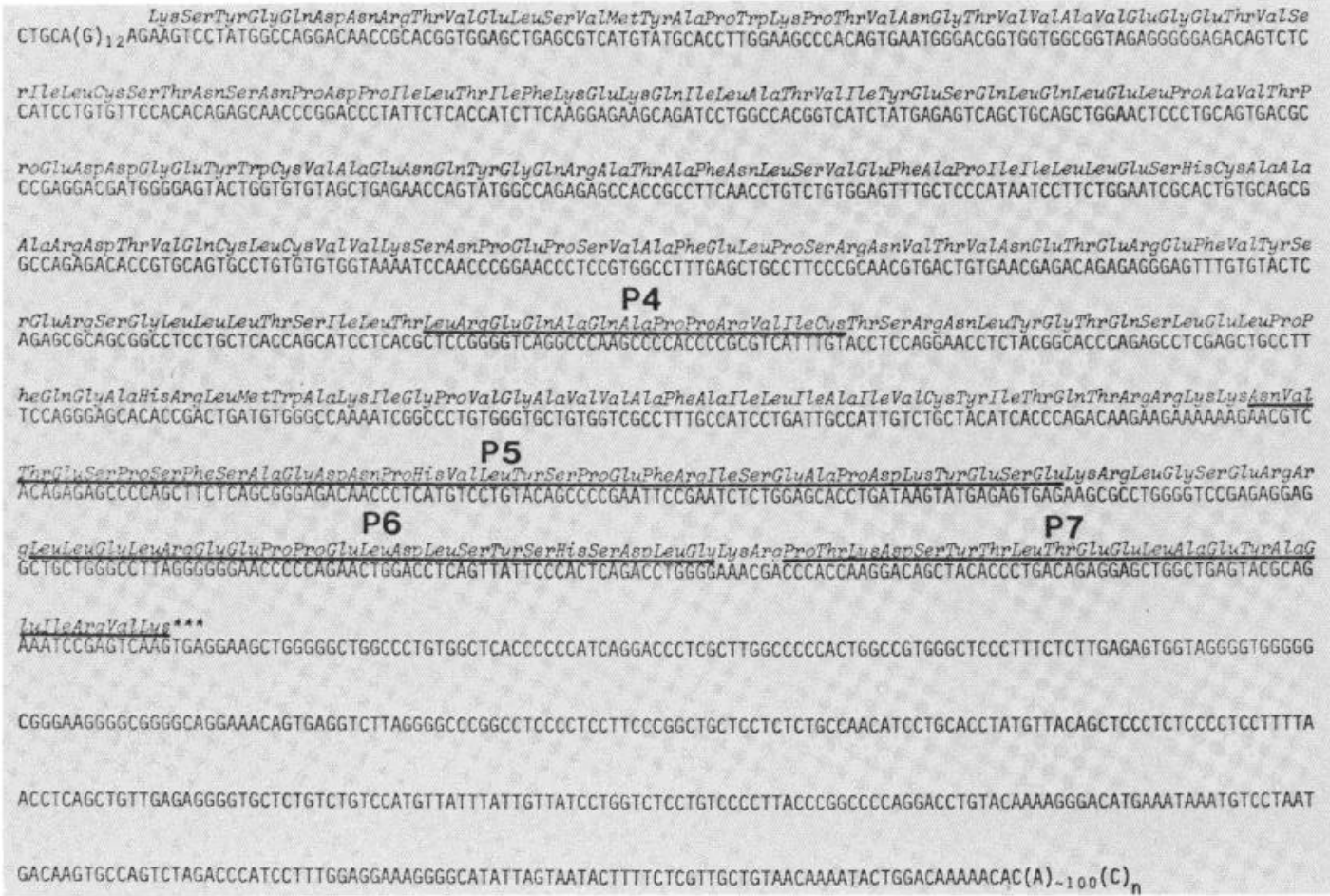

Figure 1. Nucleotide sequence of the p1B236 cDNA insert, showing the open reading frame 318 amino acids long, and the positions of the synthetic peptides $(P 4, P 5, P 6$, and $P 7)$ used for immunization of rabbits, and the preparation of antisera for immunocytochemistry. 
unreacted cellular elements, sections were additionally exposed to the following procedure after the final development of the HRP reaction product and rinsing. Sections were incubated in $0.1 \%$ osmium tetroxide in $0.15 \mathrm{M}$ phosphate buffer for $90 \mathrm{sec}$ at room temperature and then rinsed in distilled water; this exposure enhanced the overall degree of optical density of the HRP reaction product without modifying the background density. Selected sections were counterstained in Richardson's stain (Richardson et al., 1960) for 20 to 45 sec, depending on section thickness, dehydrated in graded ethanols, and coverslips mounted with Permount. Rat brain structures were identified and named according to the atlas of Paxinos and Watson (1982).

For electron microscopy, best results with these antisera were obtained by extending the primary immersion fixation step to 8 to $12 \mathrm{hr}$, eliminating al sucrose and Triton X-100 exposures, rinsing the tissue briefly in phosphatebuffered saline, and cutting 50 - to $70-\mu \mathrm{m}$ Vibratome sections immediately after postfixation. In experiments using the indirect two-step immunoperoxidase method, primary and secondary antibody reaction times were extended to 24 to $48 \mathrm{hr}$. An indirect, four-step, immunoperoxidase protocol (Bloom et al., 1979) was also used on similar sections, and the individual antibody incubation times were 12 to $24 \mathrm{hr}$. The HRP reaction for both methods was optimal at a concentration of $0.05 \%$ diaminobenzidine tetrahydrochloride (DAB; Sigma) in dilute phosphate buffer, containing $0.003 \% \mathrm{H}_{2} \mathrm{O}_{2}$. This reaction was run for 15 to $25 \mathrm{~min}$ on ice, preceded by a 20 -min preincubation in $0.05 \% \mathrm{DAB}$ at $4^{\circ} \mathrm{C}$. The HRP reaction was terminated by exposure to $1 \%$ osmium tetroxide in phosphate buffer for $1 \mathrm{hr}$. Blocks were thoroughly rinsed in saline and stained en bloc with $\uparrow \%$ uranyl acetate in $70 \%$ ethanol for 45 min, then dehydrated and embedded in Taab resin. Sections cut on a Sorvall MT-2 Ultratome were mounted on 200 mesh copper grids and viewed without additional contrast enhancement in a Zeiss EM $10 \mathrm{~B}$ microscope.

\section{Results}

Overview of neuropil immunoreactivity and specificity of staining reactions

As indicated in Table I, an extensive, but virtually identical, pattern of immunoreactive fibers was visualized throughout the normal rat CNS with antisera raised against $\mathrm{P} 5, \mathrm{P} 6$, or $\mathrm{P7}$. The immunoreactivity was especially dense in the olfactory bulb (Figs. 2 and 3 ), certain preoptic (Fig. 4) diencephalic nuclei (Figs. 5 and 6), the neostriatum (Figs. 7 and 8), and limbic (Figs. 9 and 10) and neocortical (Figs. 11 and 12) regions. Neuropil staining was also prominent within selected thalamic (Fig. 14) and cranial nerve nuclei (Figs. 15 and 17 A), as well as in cerebellum (Fig. 16) and spinal cord (Fig. 17B). All figures of neuropil immunoreactivity are presented for antisera 5858 for P5 except for Figure 11, which illustrates the immunoreactivity for all three peptides in neocortex. In maps constructed from the optimally reactive antisera for each of the three $\mathrm{C}$-terminal fragments of protein 1B236, the patterns of immunoreactivity were virtually identical (Table I. Fig. 19) with some minor exceptions discussed separately below. Immunoreactivity detected by antiserum 5751, raised against P6 and specifically blocked by absorption only with P6, gave the most intense and distinct perikaryal staining in colchicine-pretreated rats (Table II). However, all regions with neurons exhibiting intense perikaryal reaction to $\mathrm{P} 6$ also show reproducible but lesser perikaryal immunoreactivity with antisera 5858 or 5864 to $P 5$ and $P 7$, respectively. In one case (Fig. 18), antiserum 5858 (P5) detected cellular reactivity in the medial trapezoid nucleus not detected with antisera to P6 or P7. The only other exception to the superimposable maps was the immunoreactivity seen in magnocellular hypothalamic nuclei by antiserum 5864 (P7) that was not seen with antisera to P5 or P6 (Fig. 6).

Neuropil staining typically exhibited four major forms: (1) a fine varicose fiber, with positive immunoreactivity in both varicosities and intervaricose regions; (2) isolated punctate elements interpreted as immunoreactive fibers surrounding the perimeter of unreactive neurons or neurites; (3) thick, straight immunoreactive processes traveling within myelinated tracts; and (4) broad, generally long, densely immunoreactive neurites within regions shown to have immunoreactive perikarya in colchicine-treated preparations. The first two forms are interpreted as preterminal and terminal axons, the third as fibers of passage, and the fourth as probable dendrites.

Immunoreactive perikarya were difficult to detect reproducibly with any antiserum in untreated adult rats. However, immunoreactive
TABLE ।

Peptide 236 distribution by immunocytochemistry

The density of immunoreactive neuropil in each indicated rat brain structure was evaluated in untreated rats with antisera to P5, P6, or P7, and rated on a scale of 1 (least) to 4 (most), as indicated by the number of + symbols. Areas in which neuropil was nonreactive are not included. Note that with the rare exceptions noted in the text, the pattern of intensities of immunoreactivity across these regions varies identically with antisera directed against the adjacent but nonhomologous peptide fragments of the polypeptide structure deduced from the $1 \mathrm{~B} 236 \mathrm{mRNA}$.

\begin{tabular}{|c|c|c|c|}
\hline Region & Peptide 5 & $\begin{array}{l}\text { Neuropil } \\
\text { Peptide } 6\end{array}$ & Peptide 7 \\
\hline \multicolumn{4}{|l|}{ Olfactory bulb } \\
\hline Internal granule cell layer & ++++ & ++++ & $++t+$ \\
\hline \multicolumn{4}{|l|}{ Forebrain } \\
\hline Anterior olfactory nuclei & ++++ & ++++ & ++++ \\
\hline Olfactory tubercle & ++++ & ++++ & ++++ \\
\hline Bed nucleus stria terminalis & ++++ & ++++ & +++ \\
\hline Lateral septal nuclei & ++++ & ++++ & ++++ \\
\hline Primary olfactory cortex & +++ & +++ & +++ \\
\hline Caudate/putamen & ++++ & ++++ & ++++ \\
\hline Parietal cortex & ++++ & ++++ & ++++ \\
\hline Cingulate gyrus (midposterior) & ++++ & ++++ & ++++ \\
\hline Subiculum & ++++ & ++++ & ++++ \\
\hline Hippocampus (CA3 $>>C A 1)$ & ++++ & ++++ & ++++ \\
\hline $\begin{array}{l}\text { Amygdala (basolateral, medio- } \\
\text { cortical) }\end{array}$ & +++ & +++ & +++ \\
\hline \multicolumn{4}{|l|}{ Diencephalon-midbrain } \\
\hline Preoptic area & ++++ & ++++ & ++++ \\
\hline $\begin{array}{l}\text { Dorsomedial nucleus, ventro- } \\
\text { lateral and ventroposterola- } \\
\text { teral thalamic nuclei }\end{array}$ & +++ & $+t+$ & $+t+$ \\
\hline $\begin{array}{l}\text { Paraventricular nucleus, hypo- } \\
\text { It halamius }\end{array}$ & +++ & +++ & +++ \\
\hline Medial forebrain bundle & +++ & +++ & +++ \\
\hline Arcuate nucleus & ++ & ++ & ++ \\
\hline Inferior colliculi & +++ & +++ & +++ \\
\hline Superior colliculi & $+t$ & ++ & ++ \\
\hline Periaqueductal gray & ++ & ++ & ++ \\
\hline \multicolumn{4}{|l|}{ Brainstem } \\
\hline Substantia nigra & + & + & + \\
\hline Locus ceruleus & + & + & + \\
\hline Central gray & +++ & +++ & +++ \\
\hline Dorsal, pontine raphe nuclei & + & + & + \\
\hline Dorsal cochlear nucleus & +++ & +++ & +++ \\
\hline Motor $V, V I I, I X, X, X \|$ & +++ & +++ & +++ \\
\hline Inferior olive & ++ & ++ & ++ \\
\hline Medial trapezoid nucleus & ++ & ++ & ++ \\
\hline \multicolumn{4}{|l|}{ Cerebellum } \\
\hline Granular cell layer & ++++ & ++++ & ++++ \\
\hline Molecular layer (proximal) & ++ & ++ & ++ \\
\hline Deep cerebellar nuclei & $++t$ & 0 & 0 \\
\hline \multicolumn{4}{|l|}{ Spinal cord } \\
\hline Dorsal horn (II-III) & +++ & +++ & +++ \\
\hline Ventral horn & +++ & +++ & +++ \\
\hline Central gray & ++ & ++ & ++ \\
\hline
\end{tabular}

perikarya were numerous in rats pretreated with colchicine (see Table II. Figs. 2, 4, 7, 8, 10, and 12). Neuropil immunoreactivity was reduced but not eliminated in certain structures when perikaryal immunoreactivity became detectable. Presumptive perikarya typically showed one of two major patterns of immunoreactivity. The major class of immunoreactive neurons had a conventional morphology, generally exhibiting multipolar dendritic processes, varying in size and orientation according to their location. These neurons were prominent in the nuclei of the olfactory peduncle and several secondary olfactory targets (Fig. 4), the amygdala (see Fig. 10), the 
Figure 2. Olfactory bulb. Intense immunoreactivity is seen within the perimeters of the glomeruli $(G)$, where immunoreactive periglomerular neurons (arrow in inset at top) can be observed in colchicine-pretreated rats. The olfactory nerve layer $(O)$ showed no immunoreactivity. The external plexiform layer $(E)$ contained long, fine, smooth immunoreactive processes, but the mitral cell layer $(M)$ showed no immunoreactivity. Extensive fiber staining was observed surrounding the granule cells in the internal plexiform layer $(I)$. Calibration Bar $=$ $100 \mu \mathrm{m}$; inset $=50 \mu \mathrm{m}$.

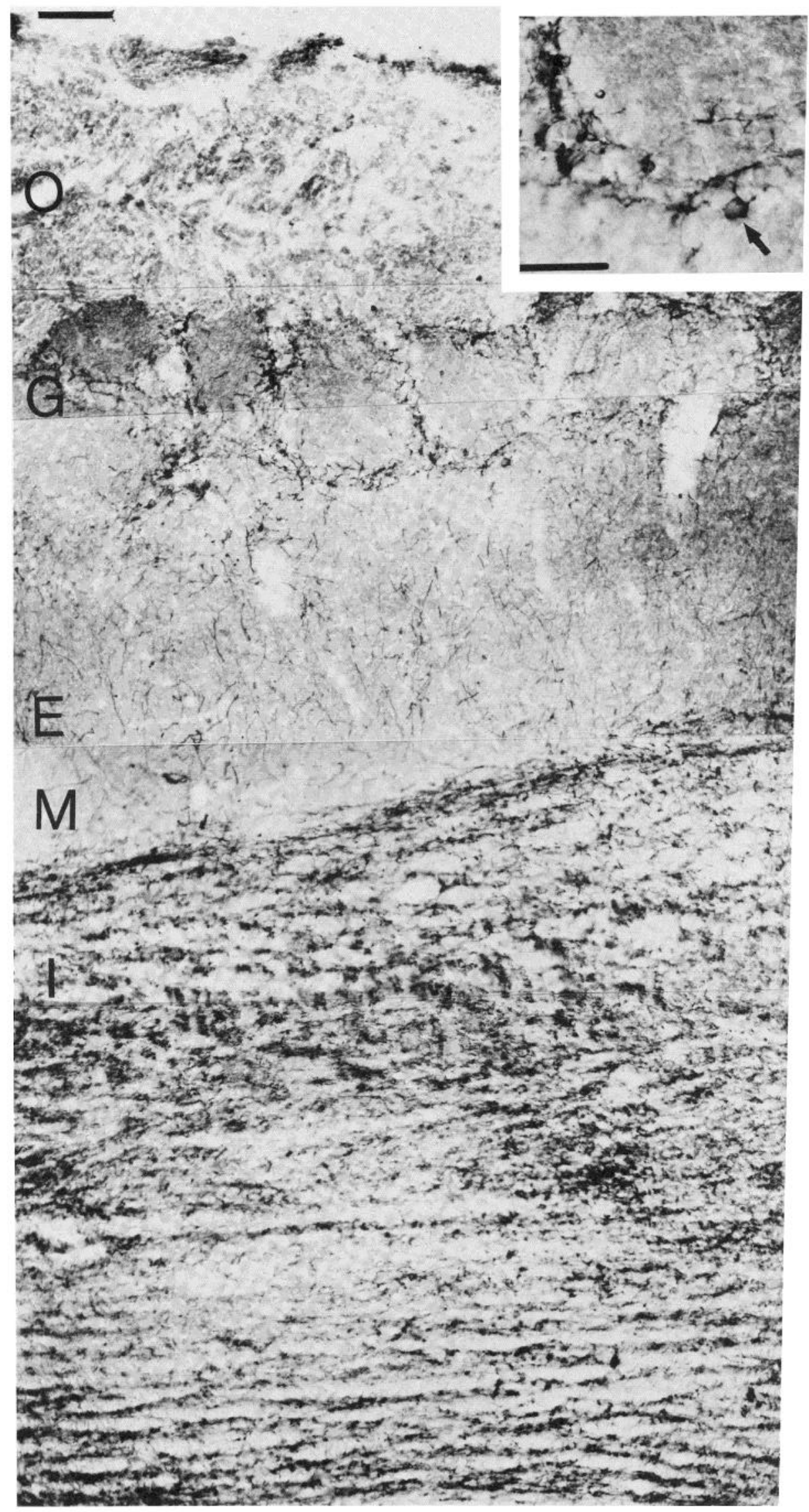



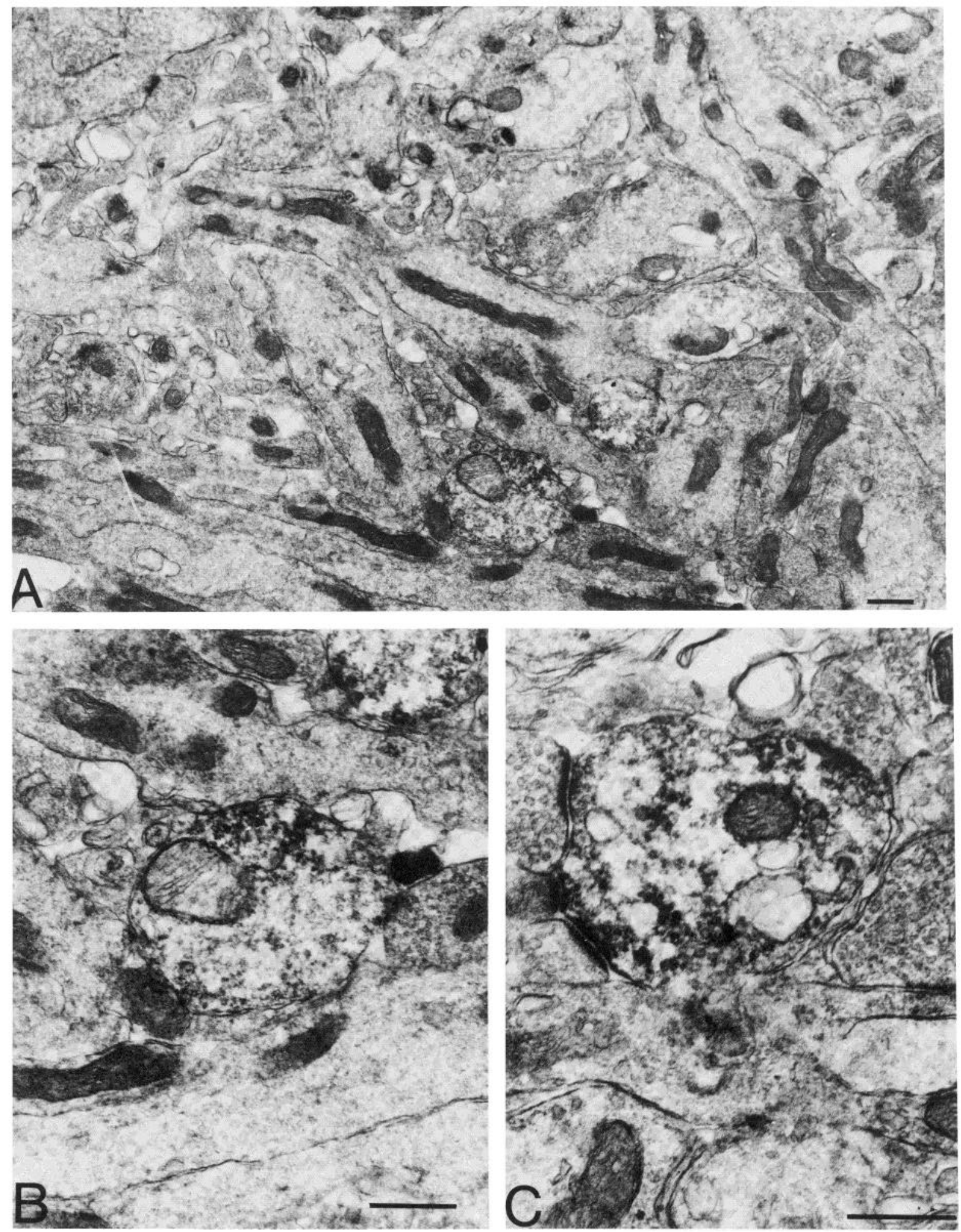

Figure 3. $A$ to $C$ are electron microscopic localizations of $1 \mathrm{~B} 236 \mathrm{P} 5$ immunoreactivity within the internal plexiform layer within presumptive nerve terminal structure ( $A$ and $B$ are at higher magnification) and an immunoreactive postsynaptic structure $(C)$ that also contains some immunoprecipitates surrounding small lucent synaptic vesicles. Calibration bars $=0.5 \mu \mathrm{m}$.

piriform cortex, and certain other sites (see Table I). The second type of presumptive neuron was seen most prominently in the striatum (see Fig. 8), diencephalon, pons, and brainstem. These neurons, referred to as "hairy" cells, exhibited multiple dendritic-like elements that emerged from the cytoplasm surrounding a metachromatic nonimmunoreactive nucleus when counterstained. These dendrite-like processes could be short or long. In the latter case they would frequently stream away from the perikaryon in a direction 


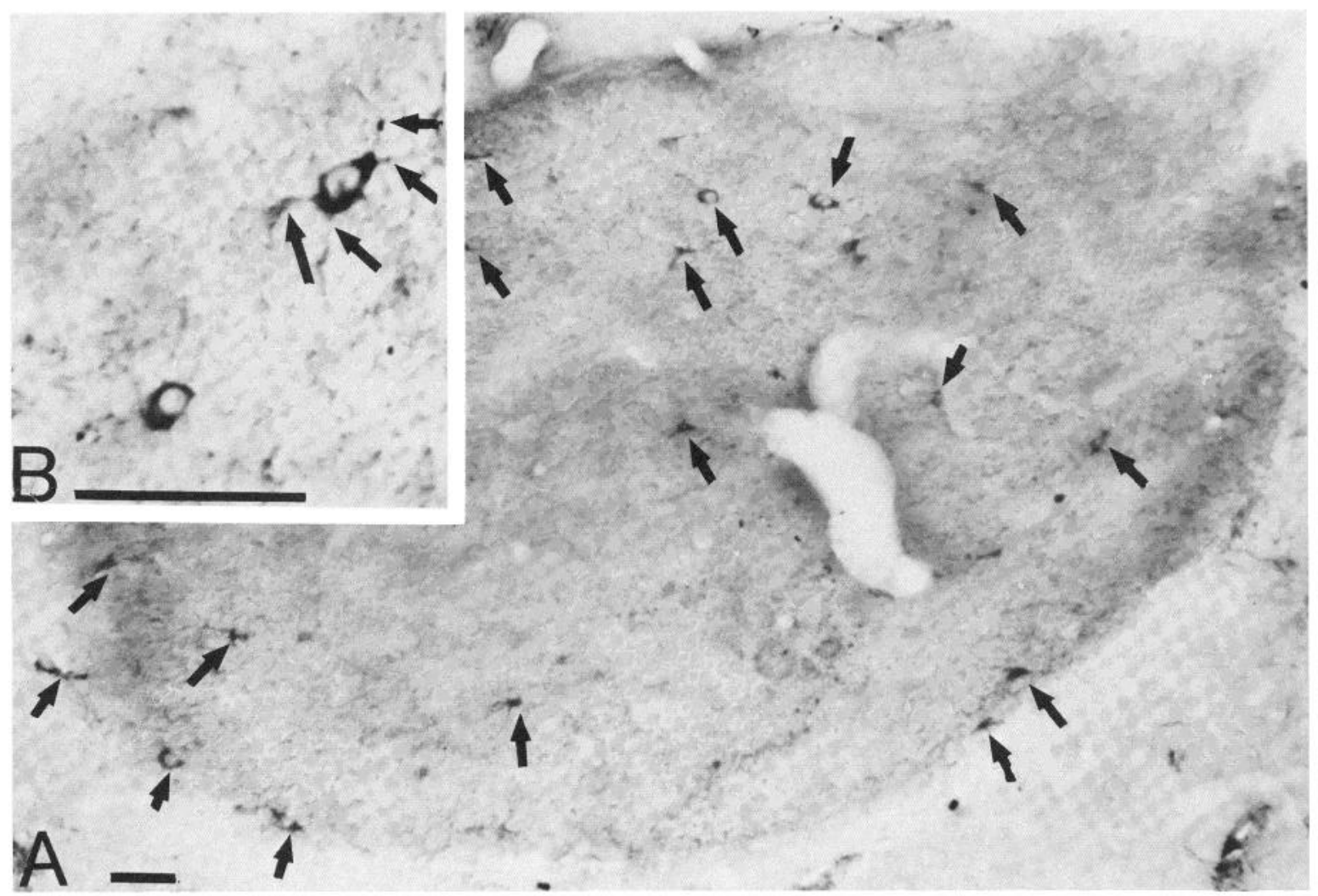

Figure 4. A, Large multipolar neurons (arrows) found within the white matter of the anterior commissure and its nucleus, in colchicine-pretreated rats exposed to antisera to P6. Such neurons were typical of all accessory olfactory nuclei within the olfactory peduncle and were also seen within the polymorphic layers of the primary olfactory cortex. B (inset) shows two neurons at higher magnification to illustrate a large polymorphic neuron of which the dendrites (arrows) lie above and below the focal plane. Calibration bars $=50 \mu \mathrm{m}$.

parallel to its long axis. In striatal, thalamic, piriform, and midbrain structures, both classes of neurons were intermingled (see Fig. 8).

\section{Summary of major patterns of immunoreactivity}

The following descriptions summarize the major patterns of immunoreactivity within regions showing prominent staining in both neuropil components (normal rats) and perikarya (colchicine-treated rats) from rostral to caudal regions.

Olfactory bulb and penduncle. Intense immunoreactivity was seen within the perimeters of the glomeruli, where immunoreactive periglomerular neurons (Fig. 2, inset) were observed in colchicine-pretreated rats. The external plexiform layer and mitral cell layer showed no immunoreactivity, whereas extensive fiber staining was observed surrounding the unreactive granule cells in the internal plexiform layer. In favorable sections, isolated small neurons, interpreted as short-axon cells, could be resolved in the outer third of the internal plexiform layer. Preliminary electron microscope localization of immunoreactivity for P5 in the olfactory bulb (Fig. 2) confirmed the reactivity within dendrites and perikarya of the periglomerular neurons and in fine nerve terminals synapsing on small dendritic spines within the internal plexiform layer. In immunoreactive terminals, the reaction product was mainly associated exclusively with the cytoplasmic face of the synaptic vesicles.

In the olfactory peduncle, extensive neuropil immunoreactivity was observed in each of the olfactory nuclei and the transition zones in the anterior olfactory cortex. Both fibers of passage and finer processes with relatively few varicosities were observed to collect at the lateral ventral pole of the peduncle, and entering the inner surface of the lateral olfactory tract. Fiber-like staining was not seen within the anterior commissure. In colchicine-pretreated rats, large and medium-sized multipolar neurons were also seen in all nuclear fields of the peduncle, as well as within and around the nucleus of the anterior commissure and the nucleus of the lateral olfactory tract. Such neurons were always a minor fraction of the total neuronal population visualized in these fields by general cytoplasmic counterstaining, but they formed a larger proportion of the neurons in the nucleus of the anterior commissure and in its anterior extension (Fig. 4) than in the other olfactory peduncle nuclei.

Basal telencephalon. The ventral preoptic region showed a dense fiber plexus surrounding the ventral perimeter of the anterior commissure at the level of the bed nucleus of the stria terminalis. Medially (see Fig. $5 \mathrm{~A}$ ), in the region of the vertical limb of the diagonal band, larger and thicker immunoreactive structures, suggestive of fibers of passage, were observed. In colchicine-pretreated rats, some partly filled perikarya or the proximal dendrites of unstained or lightly stained perikarya were seen. These neurons were roughly elliptical, with the long axis measuring 25 to $40 \mu \mathrm{m}$ and the narrow axis measuring 10 to $15 \mu \mathrm{m}$. Surrounding these perikarya were multiple fine, short, immunoreactive fibrils, generally oriented along the long axis of the perikaryon. Such neurons were undetectable without colchicine pretreatment, but their appearance was unrelated to the interval between colchicine injection and fixation.

In the paraventricular nucleus of the hypothalamus and other magnocellular regions, immunoreactivity was visualized in a dense plexus of thick, straight processes surrounding unreactive neurons (Fig. 5B). Since no immunoreactive perikarya were seen in these regions with two of our three most sensitive antisera, even in colchicine-pretreated rats, these structures were interpreted as " $\mathrm{fi}$ bers." More varicose, and isolated, small immunoreactive structures, interpreted as preterminal and terminal fibers, respectively, were also visualized. Antisera raised against P7 detected specific immunoreactivity within the magnocellular neurons of the paraventricular and supraoptic nuclei (Fig. 6). These perikaryal immunoreactivities were never seen with antisera to P5 or P6 (Table III). However, in untreated 
TABLE ॥

Peptide 236 distribution by immunocytochemistry of cell bodies. (colchicine-treated rats)

The density of perikarya immunoreactive with antisera to $\mathrm{P} 5, \mathrm{P} 6$, or $\mathrm{P} 7$ in rats treated with intracisternal injection of colchicine is indicated. Although the most intense parikaryal immunoreactivity was revealed by exposure to antisera against $P 6$, regions with cells showing immunoreactivity to $P 6$ were also detectable with antisera to P5 or P7, with the exceptions noted in the text.

\begin{tabular}{|c|c|c|c|}
\hline Region and Cell Type & Peptide 5 & Peptide 6 & Peptide 7 \\
\hline \multicolumn{4}{|l|}{ Olfactory bulb } \\
\hline Periglomerular cells & ++ & ++++ & + \\
\hline \multicolumn{4}{|l|}{ Forebrain } \\
\hline Anterior olfactory nuclei & ++ & ++++ & ++ \\
\hline Corpus callosum & $+1-$ & ++++ & + \\
\hline Parietal cortex, III, V & + & +++ & + \\
\hline Cingulate cortex $V$ & + & ++ & + \\
\hline Subcortical white matter & $+1-$ & +++ & + \\
\hline Basolateral amygdala & $+1-$ & ++++ & $+1-$ \\
\hline Medial cortical amygdala & $+1-$ & ++++ & $+1-$ \\
\hline Central nucleus, amygdala & 0 & ++ & 0 \\
\hline Endopiritorm nucleus & $+1-$ & +++ & $+1-$ \\
\hline Caudate putamen & + & +++ & + \\
\hline Bed nucleus stria terminalis & + & +++ & + \\
\hline $\begin{array}{l}\text { Dorsal and medial septal nu- } \\
\text { clei }\end{array}$ & 0 & ++ & 0 \\
\hline Primary olfactory cortex & + & ++ & + \\
\hline \multicolumn{4}{|l|}{ Diencephalon } \\
\hline $\begin{array}{l}\text { Paraventricular/supraoptic hy- } \\
\text { pothalamus }\end{array}$ & 0 & 0 & +++ \\
\hline Nucleus reticularis thalami & + & ++ & + \\
\hline Intralaminar nuclei, thaiamus & + & ++ & + \\
\hline Dorsal premammillary nucleus & + & ++ & + \\
\hline Supramammillary nucleus & 0 & + & 0 \\
\hline $\begin{array}{l}\text { Ventrolateral, ventrobasal nu- } \\
\text { clei, thalamus }\end{array}$ & 0 & ++ & 0 \\
\hline \multicolumn{4}{|l|}{ Brainstem } \\
\hline Medial trapezoid nucleus & +++ & 0 & 0 \\
\hline $\begin{array}{l}\text { Substantia nigra, pars com- } \\
\text { pacta }\end{array}$ & + & ++ & + \\
\hline Pontine nuclei & $+1-$ & + & $+1-$ \\
\hline \multicolumn{4}{|l|}{ Cerebellum } \\
\hline "Golgi" cells & +++ & +++ & +++ \\
\hline \multicolumn{4}{|l|}{ Spinal cord } \\
\hline Dorsal horn cells (II, III) & ++ & ++ & ++ \\
\hline Intermediolateral cell columns & + & ++ & + \\
\hline
\end{tabular}

rats, antisera to all three peptides did reveal immunoreactive fiberlike staining here (Fig. 5B), raising the possibility that the straight processes seen here represent dendrites rather than afferent axons from other regions.

Basal ganglia. Intense immunoreactivity was detected within the striate fiber bundles of the caudate nucleus and the densely immunoreactive, long, branching, fiber-like processes seen within the internal capsule and permeating the striatum (Figs. 7 to 9). In serially collected sections, these fibers could be traced into the external perimeter of the striatum from regions of cortex identified by Nissl staining patterns as both somatosensory and motor and temporal cortex. Immunoreactive fibers could be seen coursing from the deep cortical layers through the subcortical white matter, and forming into fascicles at the surface of the striatum. In sagittal sections, these fibers permeated the entire striatum, concentrating in the ventral pallidal area. At higher magnifications, a small fraction of the thick fibers of passage could be seen to divert from a thick fascicle to enter the generally unreactive interfascicle neuropil. Such emerging fibers then took on the appearancc of typical pretcrminal axons with fine varicosities 2 to 3 times the thickness of the intervaricose regions. In the neuropil regions of the striatum, widely separated immunoreactive perikarya were often seen, with no particular regional concentration within the striatum. A typical reactive perikaryon from the caudate nucleus of a colchicine-treated rat (Fig. 8) is typical of the second pattern of staining (i.e., "hairy" cells) within large, multipolar neurons.

Hippocampal formation. Extensive immunoreactive fibers surround the perikarya and apical dendrites of pyramidal neurons in all CA fields but are most extensive in CA3/4. These fibers could be traced to the fimbria, were present along the anterior third of the fornix in sagittal sections, and could be followed to thick processes emerging from the medial and dorsal-medial nuclei of the septum in colchicine-treated rats (Fig. 10).

In the dentate gyrus, the densest neuropil immunoreactivity was seen in the outer molecular layer. The granule cell layer itself showed only rare, fine fibers. In favorable series of sections, the immunoreactive fibers entering the outer molecular layer of the dentate gyrus could be traced back to the perforant pathway. These fascicles were particularly dense at the transition between the dentate and the outer CA3 molecular layer (see Fig. 9A). In colchicine-pretreated rats, large multipolar neurons were prominent within the endopiriform nucleus (Paxinos and Watson, 1982), the piriform cortex, and other cortical fields deep to and ventral to the rhinal sulcus.

Large, separated immunoreactive perikarya were detected within the basolateral amygdaloid nucleus (Fig. 10). Similar immunoreactive cells were observed within laminae $\|$ and III of the endopiriform nucleus, and in lesser frequency within the mediocortical nucleus of the amygdala, in the polymorphic zone of the primary olfactory cortex, and occasionally in the lateral insular cortex just dorsal to the rhinal fissure.

Cerebral cortex. In cerebral cortex, neuropil immunoreactivity for P5, P6, and P7 showed virtually identical region-specific patterns when compared over the major cortical regions. Based upon published topographic and cytological critiera for rat cortical regions (Krieg, 1946; Krettek and Price, 1977a, b; Wise et al., 1979; Vogt and Peters, 1981; Luskin and Price, 1983; Welker and Woolsey, 1975 ), it was possible to correlate $1 \mathrm{~B} 236$ immunoreactivity with presumptive functionally defined regions of rat cerebral cortex. Somatosensory cortex was the predominant region of cortical immunoreactivity; posterior cingulate cortex showed intermediate immunoreactivity, with motor, temporal (auditory) fields, and the occipital (visual) cortex showing low density immunoreactivity; anterior cingulate cortex and, in particular, the frontal medial cortex had no immunoreactivity. These regional variations were consistent from antibody to antibody and from animal to animal, regardless of the plane of section.

Within the parietal and posterior cingulate cortex, intense, radially oriented immunoreactive processes spanned the entire cortical thick ness intermingled with fine, varicose fiber-like processes and isolated punctate structures (Fig. 11). These patterns were virtually identical for antisera against $\mathrm{P} 5, \mathrm{P} 6$, or $\mathrm{P} 7$ (Fig. 11, $A, B$, and $C$, respectively). All three sera showed sirnilar laminar patterns, with the P6 antisera showing somewhat denser overall immunoreactivity. Thick tangential processes were seen in outer lamina I, just below the pia, with relative modest reactivity within the inner zone of this lamina. The thick, radially directed processes were seen most clearly in deep laminae II and III, with dense, but finer, immunoreactive processes clustered around the perikarya in laminae IV, V, and mid-VI. Three contrasting bands of lighter immunoreactivity in deep layer $I$ and superficial layer $\|$ and in the deeper portions of layers $V$ and VI were reproducible throughout the somatosensory regions of cortex in frontal sections. Some fiber-like immunoreactive processes with distinct varicosities could also be seen within the superficial layers of the subcortical white matter.

Large multipolar neurons were also seen within the deep white matter of the parietal cortex and within the white matter of the antcrior commissurc, its nuclcus, and its anterior extension. Cells 

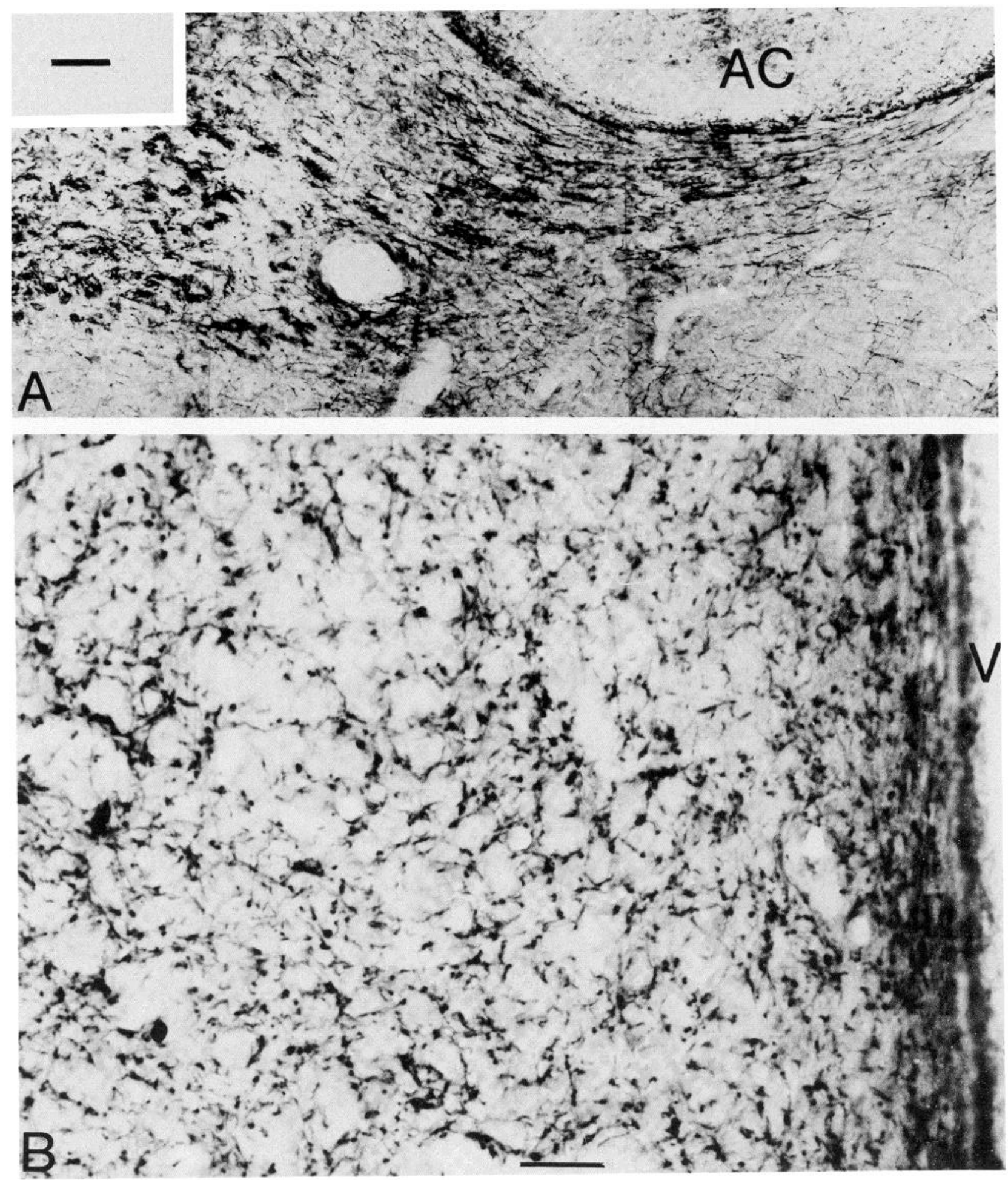

Figure 5. Basal forebrain immunoreactivity. In $A$, the preoptic region is shown in sagittal section, revealing a dense fiber plexus surrounding the ventral perimeter of the anterior commissure $(A C)$, at the level of the bed nucleus of the stria terminalis. Anteriorly (left), in the ventral region of the vertical limb of the diagonal band, larger thicker immunoreactive structures are observed, which are interpreted as either partially reacted perikarya or proximal dendrites. Calibration bar $=100 \mu \mathrm{m}$. In $B$, the paraventricular nucleus of the hypothalamus is shown from an untreated rat. In this and other magnocellular regions, a dense plexus of thicker, straight fibers and more varicose, isolated small immunoreactive structures, interpreted as preterminal and terminal fibers, respectively, were visualized in rats not pretreated with colchicine. The ependymal surface of the third ventricle $(V)$ can be seen at far right. Calibration bar $=50 \mu \mathrm{m}$.

were detected in layers $\mathrm{V}$ and $\mathrm{VI}$ of somatosensory cortex (Fig. 12), as well as in the peripheral white matter just below lamina VI (Fig. 7). Sections taken for electron microscopic localization of P5, from mid-lamina IV, show immunoperoxidase-positive nerve terminals with reactivity associated with small, lucent synaptic vesicles (Fig. 13).
Thalamus. Densely immunoreactive neuropil was seen in several discrete thalamic nuclei (Krieg, 1948) with antisera for all three peptides but was most marked in the nucleus reticularis and in the anterior-ventral, dorsomedial, ventroposterolateral, and ventrolateral nuclei (Fig. 14). More modest immunoreactivity was seen within the 


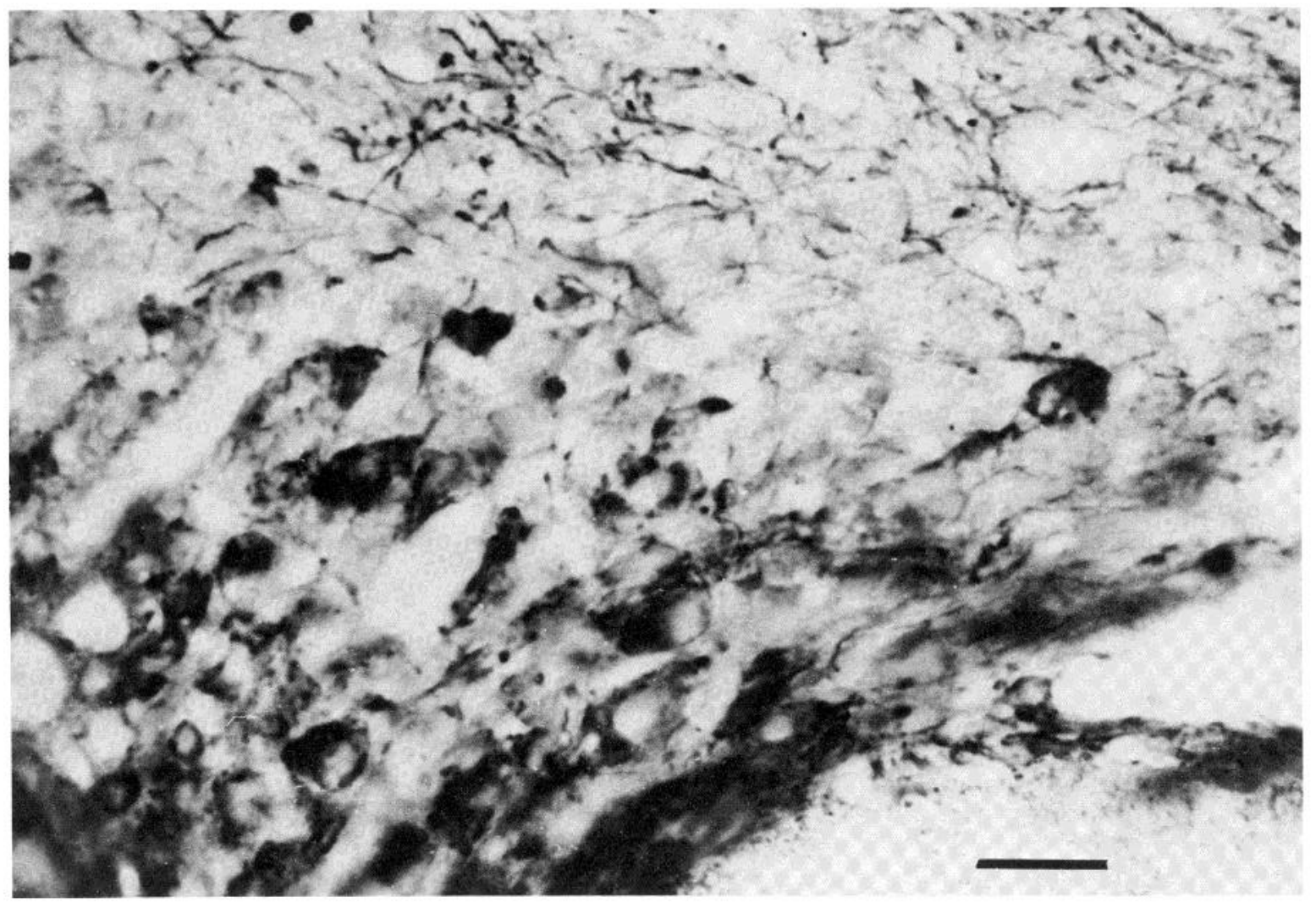

Figure 6. Antisera raised against P7 detected specific immunoreactivity within the magnocellular neurons of the supraoptic nuclei of colchicine-pretreated rats. Note the thick, smooth, straight processes at upper left and the finer varicose processes at upper right. Paraventricular nucleus neurons, not shown, were also immunoreactive to P7. These perikaryal immunoreactivities were never seen with antisera to P5 or P6, although in untreated rats, antisera to all three peptides did reveal immunoreactive fiber-like staining here. Calibration bar $=100 \mu \mathrm{m}$.

TABLE III

Differences in regional and cellular staining patterns

Although most regional and cellular staining patterns were consistent across all three $\mathrm{P}$ immunoreactivities, there were consistent differences, as illustrated in this table. These differences may reflect covert cross-reacting epitopes exposed in colchicine-treated rats or variations in post-translational processing of the $1 \mathrm{~B} 236$ protein (see the text).

\begin{tabular}{llll}
\hline \multicolumn{1}{c}{ Region } & Peptide 5 & Peptide 6 & Peptide 7 \\
\hline $\begin{array}{l}\text { Cell staining } \\
\text { Paraventricular/supraoptic } \\
\text { nuclei }\end{array}$ & 0 & 0 & ++++ \\
$\begin{array}{l}\text { Medial trapezoid } \\
\text { Fiber staining } \\
\text { Deep cerebellar nuclei }\end{array}$ & +++ & 0 & 0 \\
\hline
\end{tabular}

intralaminar nuclei. Most other thalamic nuclei showed little or no immunoreactivity, including the lateral and medial geniculate nuclei.

Densely immunoreactive neuropil was also selectively distributed within the sueprior and inferior colliculi (not shown), most clearly separated in sagittal sections. In the superior colliculus, tangential fiber-like reactive structures were seen in stratum griseum superficiale and stratum griseum intermediale (see Wise and Jones, 1977), with minimal staining in between. In inferior colliculus, fiber-like immunoreactivity extended across the upper half of the field in radially oriented structures that showed both a rostrally and a caudally oriented ascent. Less selectively oriented fiber-like immunoreactivity was also seen in the deep layers of the neuropil (stratum griseum profundum of Wise and Jones, 1977).

In colchicine-pretreated rats, immunoreactive perikarya were also seen in selected thalamic fields, generally of the "hairy" type, and were most marked in the ventrolateral nucleus and the nucleus reticularis thalami.
Pons-brain stem. Dense immunoreactivity for all three peptides was seen surrounding cranial motor neurons, most marked for facial, trochlear, trigeminal, hypoglossal, and dorsal vagal nuclei. This perisomatic, terminal-like pattern of immunoreactivity was seen surrounding the large motor nuclei (see Figs. 15 and 17A) and contrasted with the virtually undetectable immunoreactivity within the adjacent nucleus tractus solitarius and caudal vagus. Modest neuropil immunoreactivity was also observed within mid-line fields of the reticular formation, especially the region of the dorsal and median raphe nuclei, the ventral tegmentum, and the extreme lateral and medial portions of the substantia nigra, pars compacta, the endopeduncular nuclei, and the parabranchial nuclei. In colchicine-pretreated rats, antisera raised against P5 revealed dense rims of cytoplasmic immunoreactivity in neurons of the medial trapezoid nucleus after colchicine exposure (see Fig. 19 and Table III). Antisera raised against P6 and P7 showed minimal avidity for these or any other hindbrain neurons under identical conditions.

Cerebellum. Densely immunoreactive fibers were seen within the cerebellar cortex (Fig. 16A) and the interpositus nucleus (Fig. 16B). In the cortex proper, thick, branched processes were seen within the granule cell neuropil, surrounding the Purkinje perikarya and coursing horizontally across the molecular layer just superficial to the Purkinje cell layer. In the deep cerebellar nuclei, immunoreactivity to $\mathrm{P} 5$, but not to $\mathrm{P} 6$ or $\mathrm{P7}$, revealed thick, large immunoreactive elements surrounding the perimeter of the unreactive neurons. In untreated rats, small immunoreactive neurons could occasionally be recognized within the more superficial levels of the granule cell layer and, occasionally, just superficial to the Purkinje neurons. These small cells were generally oriented in the sagittal plane with thick horizontal processes extending across the apical dendrites of several Purkinje neurons. Such neurons exhibit some of the features ascribed to the Lugaro type of Golgi type II interneurons (Palay and Chan-Palay, 1974). These neurons were still recognizable after 
Figure 7. Low power sagittal view of the intense immunoreactivity within the striate fiber bundles of the caudate nucleus in a colchicine-pretreated rat. Isolated immunoreactive perikarya can be seen in the overlying white matter $(B)$. Anterior is to the right. Calibration bar $=100 \mu \mathrm{m}$.

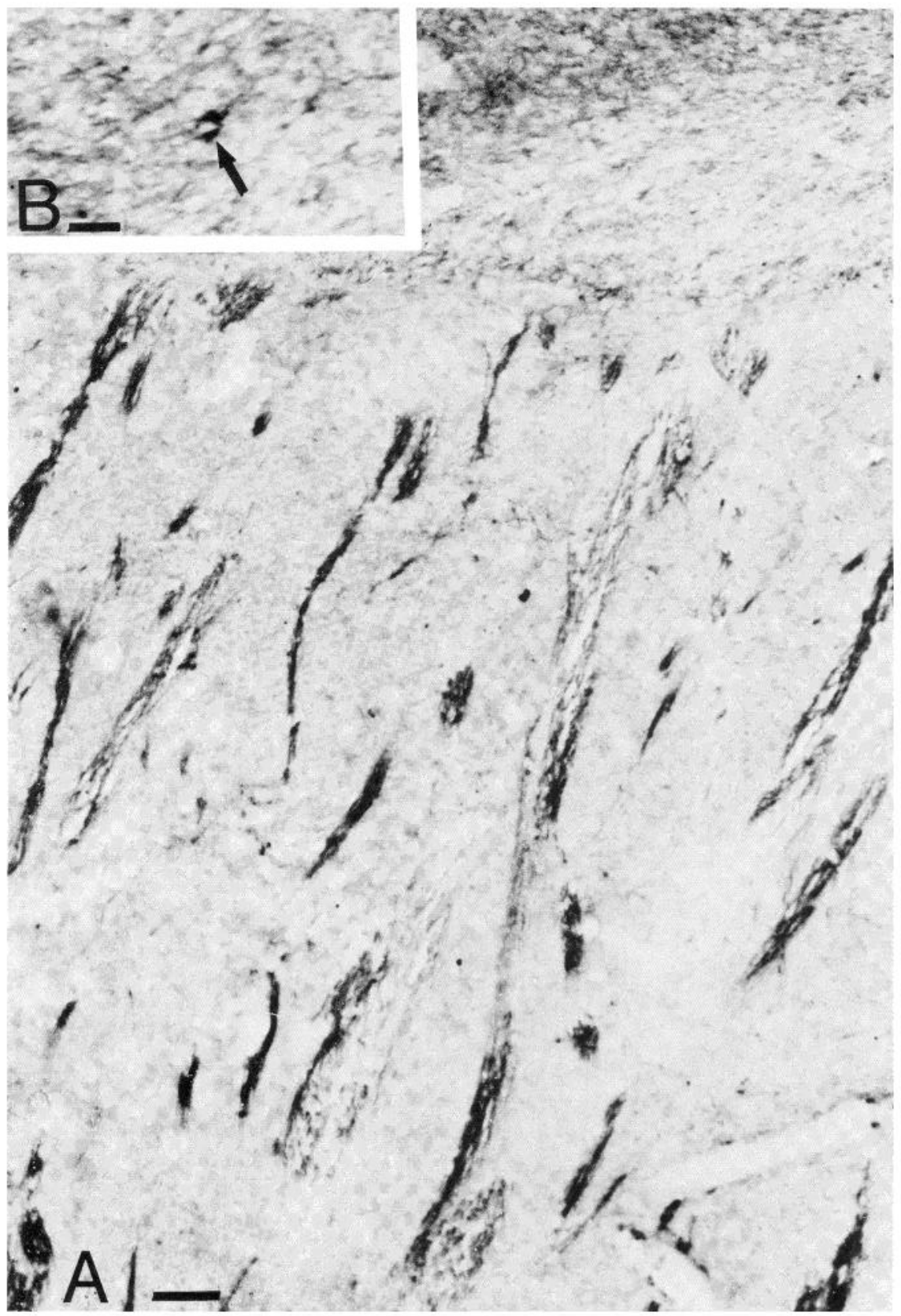

colchicine pretreatment, when the slightly reduced surrounding neuropil immunoreactivity permitted their similar perikaryal form to be recognized more easily.

Spinal cord. Dense clusters of punctate-immunoreactive elements were seen to surround the motor neurons in the trigeminal nucleus (Fig. 18A) and the ventral horn cells (Fig. 18B); intermediolateral cell columns showed patchy but occasionally intense immunoreac- tivity. No reactive elements were observed in the dorsal roots or the dorsal root ganglia, or emerging within the ventral roots. No spinal perikarya were unequivocally defined in rats treated with colchicine for 24 to $48 \mathrm{hr}$. Occasionally, small structures tentatively interpreted as neurons were visible within a densely immunoreactive field of neuropil within the substantia gelatinosa and the intermediolateral cell columns.

Figure 8. Higher power views of the immunoreactivity in the striatum. $A$, The striations of immunoreactive fibers of passage within the striatum as well as the isolated fibers that emerge from these striations to ramify within the gray matter of the caudate can be seen. Dense, long, branching fiber-like staining can be seen within the neuropil betewen the striations. $B$ (inset), A typical reactive perikaryon (arrow) from a colchicine-treated rat is shown, at the perimeter of one of the fascicles of striated fibers. $B$ also shows the immunoreactive fibers to be clustered at the perimeter of the bundle. Immunoreactive fibers of passage, preterminal axons, and four immunoreactive perikarya are shown in $C$. The two major classes of cell body detected with antisera to P6 in colchicinetreated rats can be seen (arrows). Two conventional, large multipolar neurons are seen at right, and two "hairy" cells are seen at left, one one of which ( ${ }^{\star}$. arrow) displays the fine short perisomatic structures typical of the hairy cells at somewhat lower density to render them resolvable in this focal plane. Calibration bars: $A$ and $C=25.0 \mu \mathrm{m} ; B=50 \mu \mathrm{m}$. 


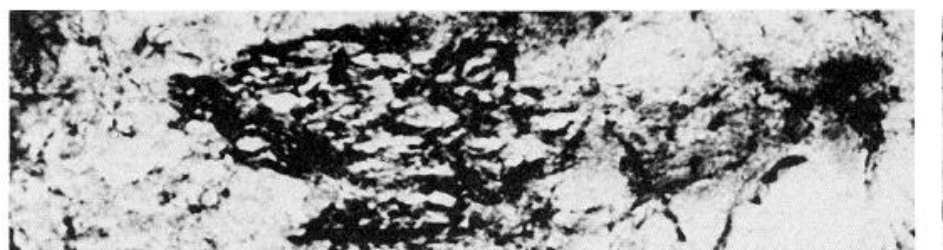

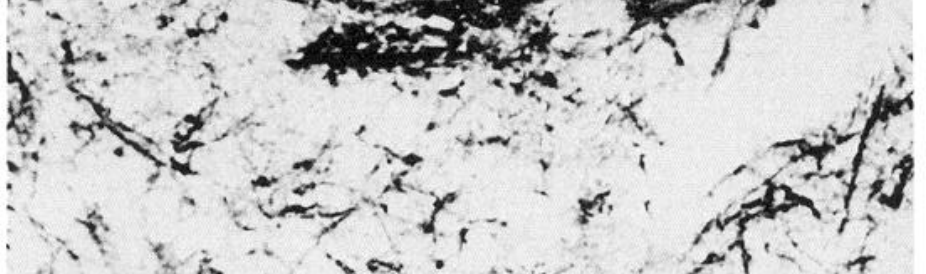
(5)

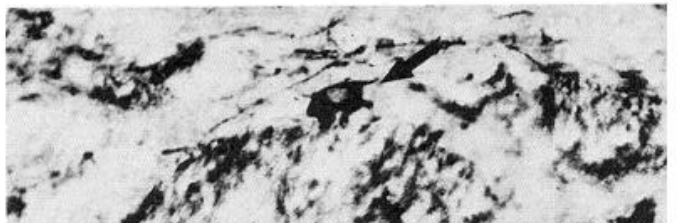

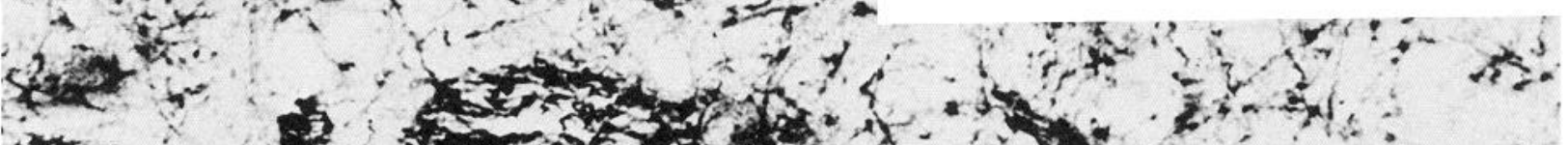

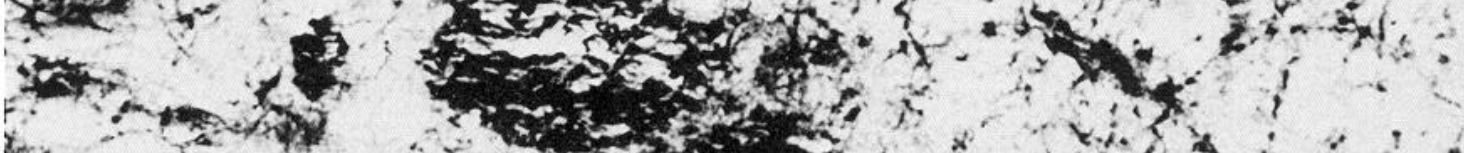

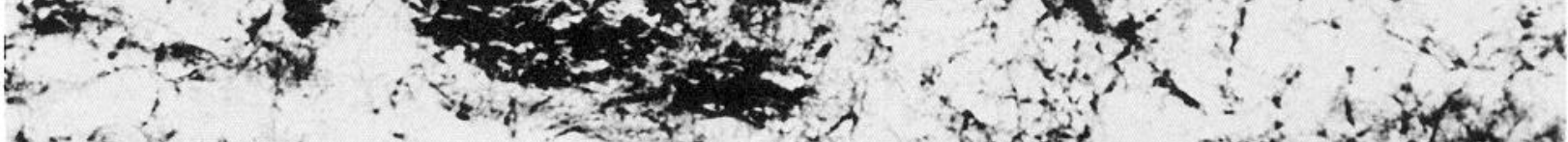
a.

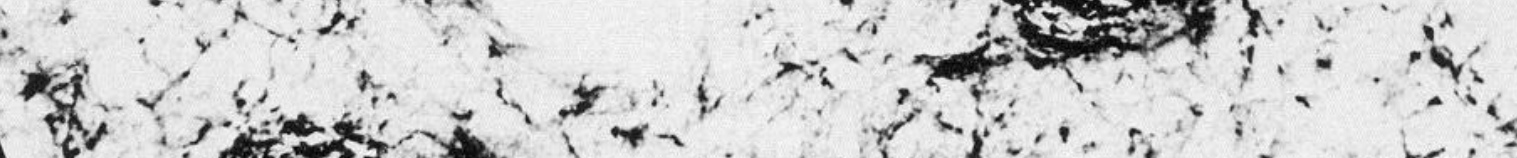

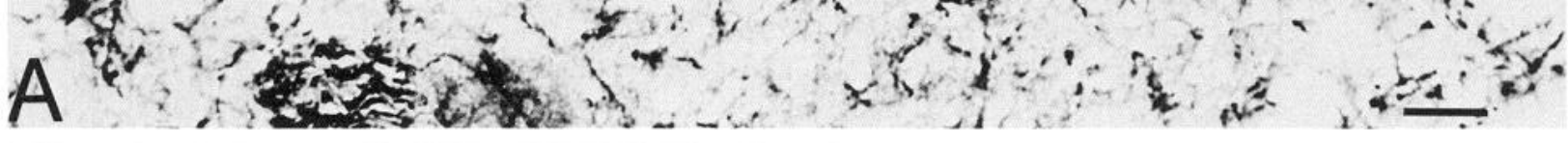

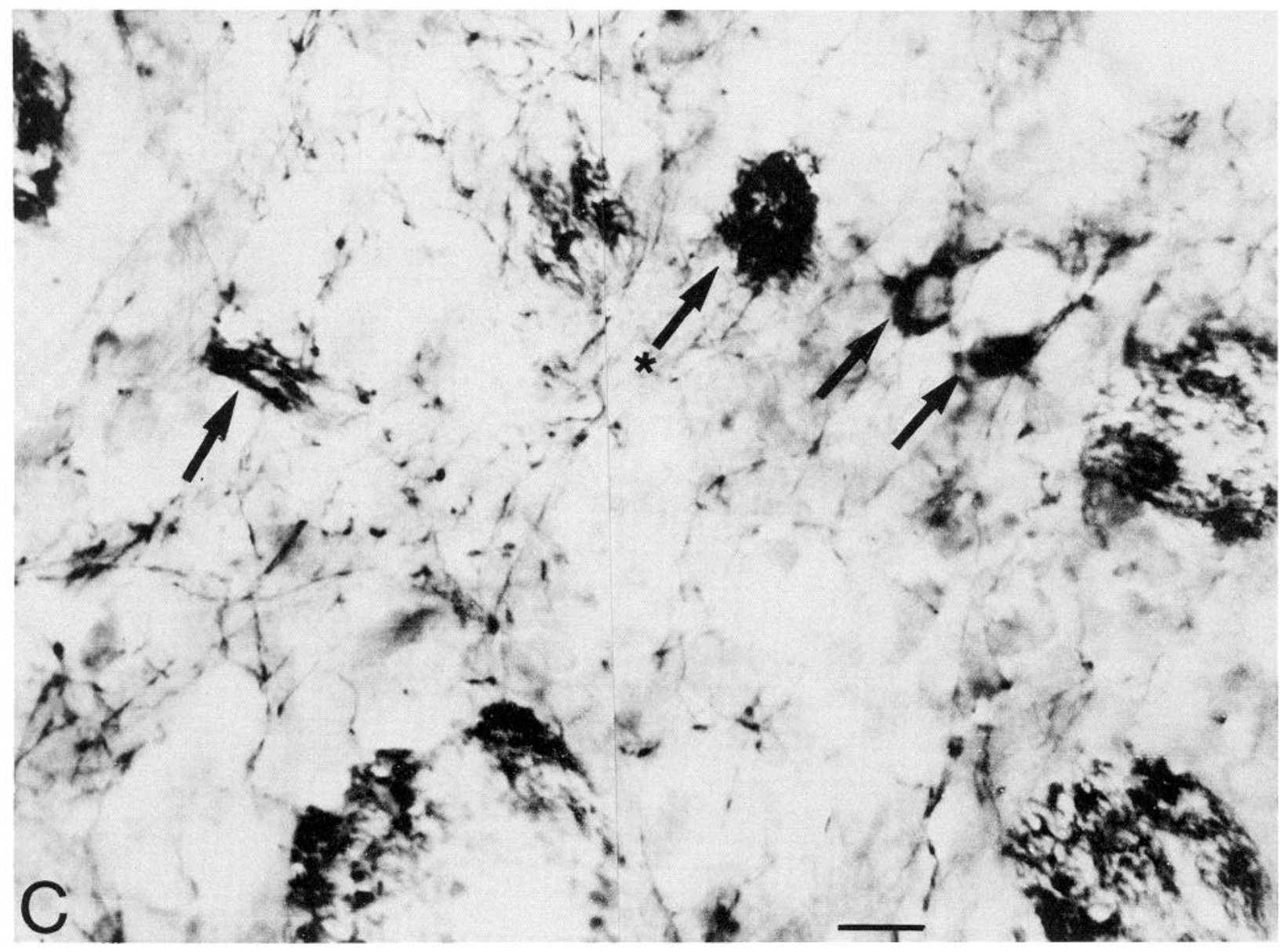



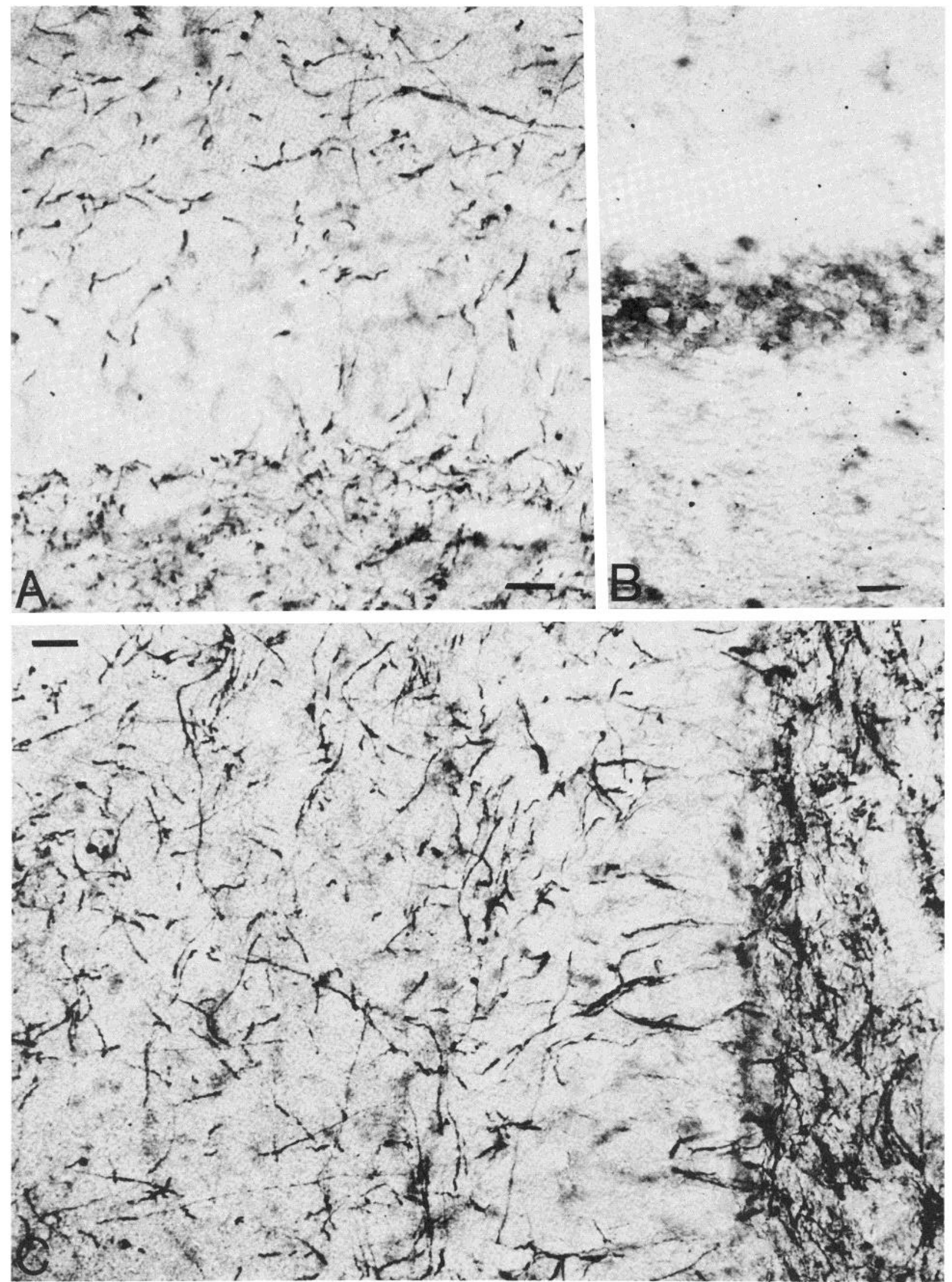

Figure 9. Extensive immunoreactive fibers surround the perikarya and apical dendrites of pyramidal cells in all fields of the hippocampal formation. In CA1 $(A)$, fiber-like immunoreactive elements are seen below and above the pyramidal cells. In dentate gyrus $(C)$, the fiber-like staining at the inner surface of the dorsal blade can be seen at far right. At this point, the inner half of the dentate molecular gyrus has more prominent immunoreactive fibers than elsewhere in the dentate gyrus. Incubation of the antiserum to P5 with synthetic P5 completely abolishes all fiber immunoreactivity ( $B$; counterstained to reveal perikarya). Calibration bars $=25 \mu \mathrm{m}$. 


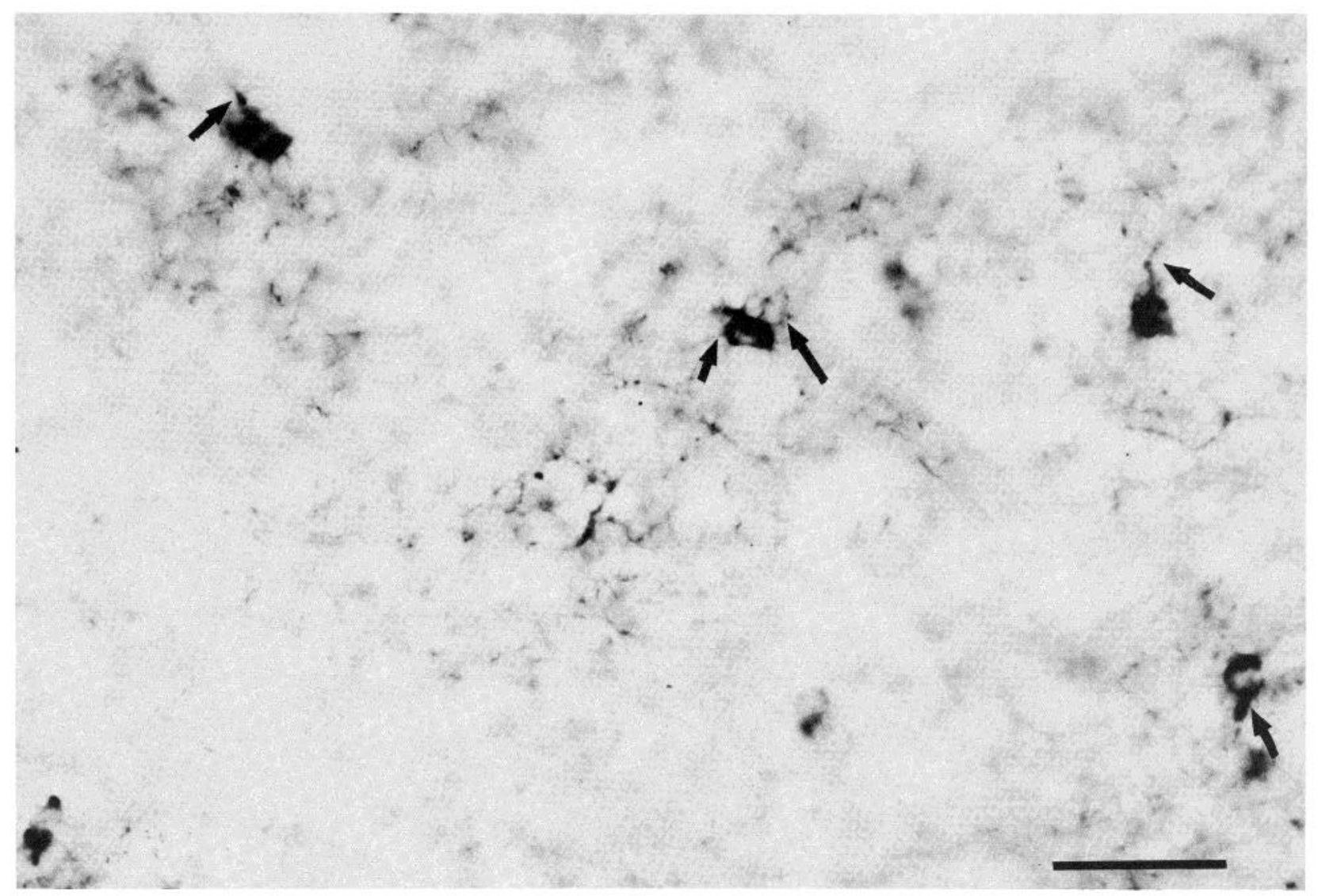

Figure 10. Large, separated immunoreactive perikarya within the basolateral amygdaloid nucleus. Arrows indicate partially reactive perikaryal processes. Similar cells were observed within laminae II and III of the piriform cortex, in the endorpiriform nucleus, and with lesser frequency within the mediocortical nucleus of the amygdala. Calibration bar $=50 \mu \mathrm{m}$.

Peripheral nervous system. No immunoreactivity was detected in superior cervical ganglia, duodenum, jejunum and transverse colon, adrenal medulla, pancreas, or kidney.

\section{Discussion}

Using immunocytochemistry and a series of antisera raised against nonoverlapping segments of a polypeptide for which the amino acid sequence was deduced from the nucleotide sequence of a brain-specific mRNA, we have mapped an extensive but selectively distributed set of neurons and fibers throughout the rat CNS (Fig. 19). Virtually identical patterns of immunoreactivity were demonstrated by antisera against either of three synthetic peptides corresponding to nonoverlapping regions of the carboxy-terminal of the presumptive polypeptide. These superimposable maps provide strong support for the interpretation that this protein, corresponding to an mRNA cloned and selected as brain specific (Sutcliffe et al., 1983), is expressed in brain and that this gene product is shared by a number of neuronal systems.

The immunoreactivity demonstrated here was not distributed throughout the nervous system as a general "neural" marker. The proportion of immunoreactive perikarya in the most heavily immunoreactive nuclear groups was estimated to be no more than $25 \%$ and, in most cases, $10 \%$ or less. In many regions with immunoreactive perikarya, the proportion of cells detected with our antisera was considerably lower. The proportion of fibers that exhibit immunoreactivity, although quite dense in some regions, can only be estimated with caution, at a few percent, pending quantitative electron immunocytochemistry. Nevertheless, the immunoreactive perikarya and the neuropil processes that extend from them are largely concentrated in cortical and subcortical structures with some known functional relationships. Indeed, based on the neural structures that are demonstrable with these antisera, certain systematic patterns emerge that may help resolve the functional nature of the shared protein they express. Immunoreactivity was intense within cortical and thalamic regions belonging to the somatosensory system, to the olfactory system, and to the major limbic structures, amygdala, hippocampal formation, and basal ganglia. Within the midbrain and spinal cord, superimposable patterns of immunoreactivity were also attributable to terminal-like contacts with cranial and spinal motor neurons and to possible links within the auditory system. The concentration of $1 \mathrm{~B} 236$ immunoreactivity within the somatosensory cortex, the limbic structures, and the olfactory system, and its more modest concentration within the motor cortex, cerebellar cortex, and motor neuron pools, thus suggests that, whatever the function of the protein, its synthesis is a property shared by these systems, and it provides some initial cellular and circuit level clues as a basis for its more definitive subsequent characterization.

Several features suggest that the neuropil immunoreactivity patterns directly reveal neuronal circuits. First, the patterns of immunoreactivity follow known laminar and nuclear planes, and parallel the circuits established by orthograde or retrograde tracing methods or by more classical metallic impregnation methods. Such features, due to their relatively increased density, are most readily recognized within the same three functional systems - the limbic, olfactory, and somatosensory systems.

Second, several distinctly neuronal elements were directly visualized within the CNS in rats pretreated with colchicine. Two conventionally recognized neuronal forms were seen. Immunoreactivity for protein 1B236 was seen within so-called local circuit neuron types, such as the periglomerular cells, cerebellar interneurons, and olfactory bulb short-axon cells. Furthermore, 1B236 immunoreactivity was also observed in typical, large, multipolar neurons prominent within the olfactory peduncle, the primary olfactory cortex, the nuclei of the amygdaloid complex, the striatum, the thalamus, the entorhinal 
Figure 11. Montage reconstructions to reveal laminar immunoreactivity patterns within somatosensory cortex following exposure to antisera against P5 $(A)$, P6 $(B)$, or P7 $(C)$. All three sera show similar laminar patterns, with the P6 antisera showing somewhat denser overall staining. Thick tangential processes are seen in outer lamina I, just below the pia, with relatively mod est reactivity within the inner zone of this lamina. Thick, radially directed processes are seen in laminae II and III, with dense, but finer, immunoreactive processes clustered around the nonimmunoreactive perikarya in laminae IV, $\mathrm{V}$, and mid-VI. The contrasting bands of lighter and denser immunoreactivity are reproducible throughout this region of cortex in frontal sections. Some fiber-like staining can also be seen within the superficial layers of the subcortical white matter at bottom. Calibration bar $=100$ $\mu \mathrm{m}$.

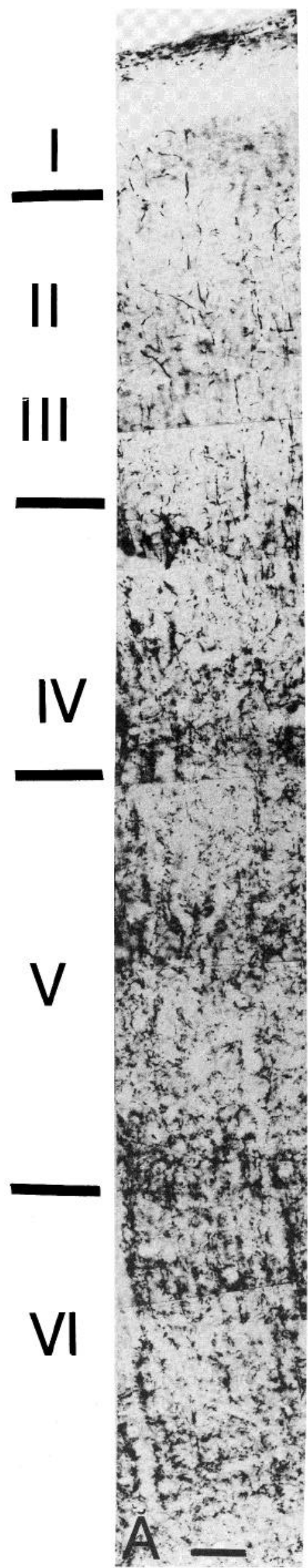

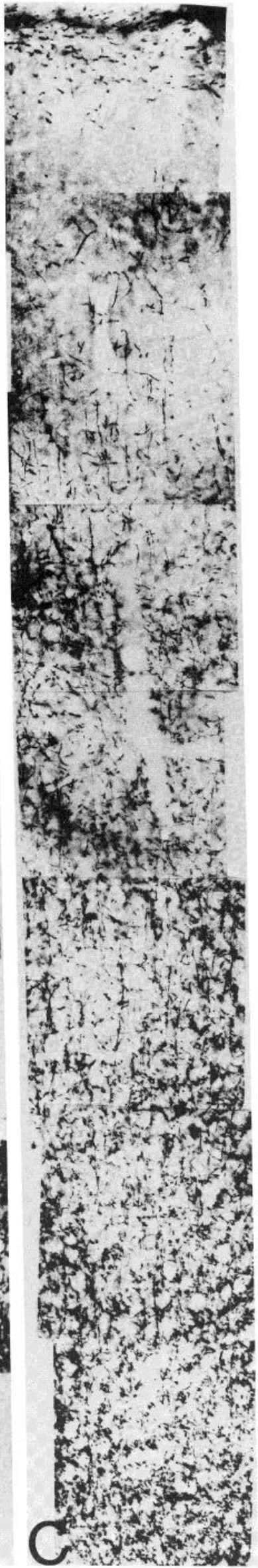



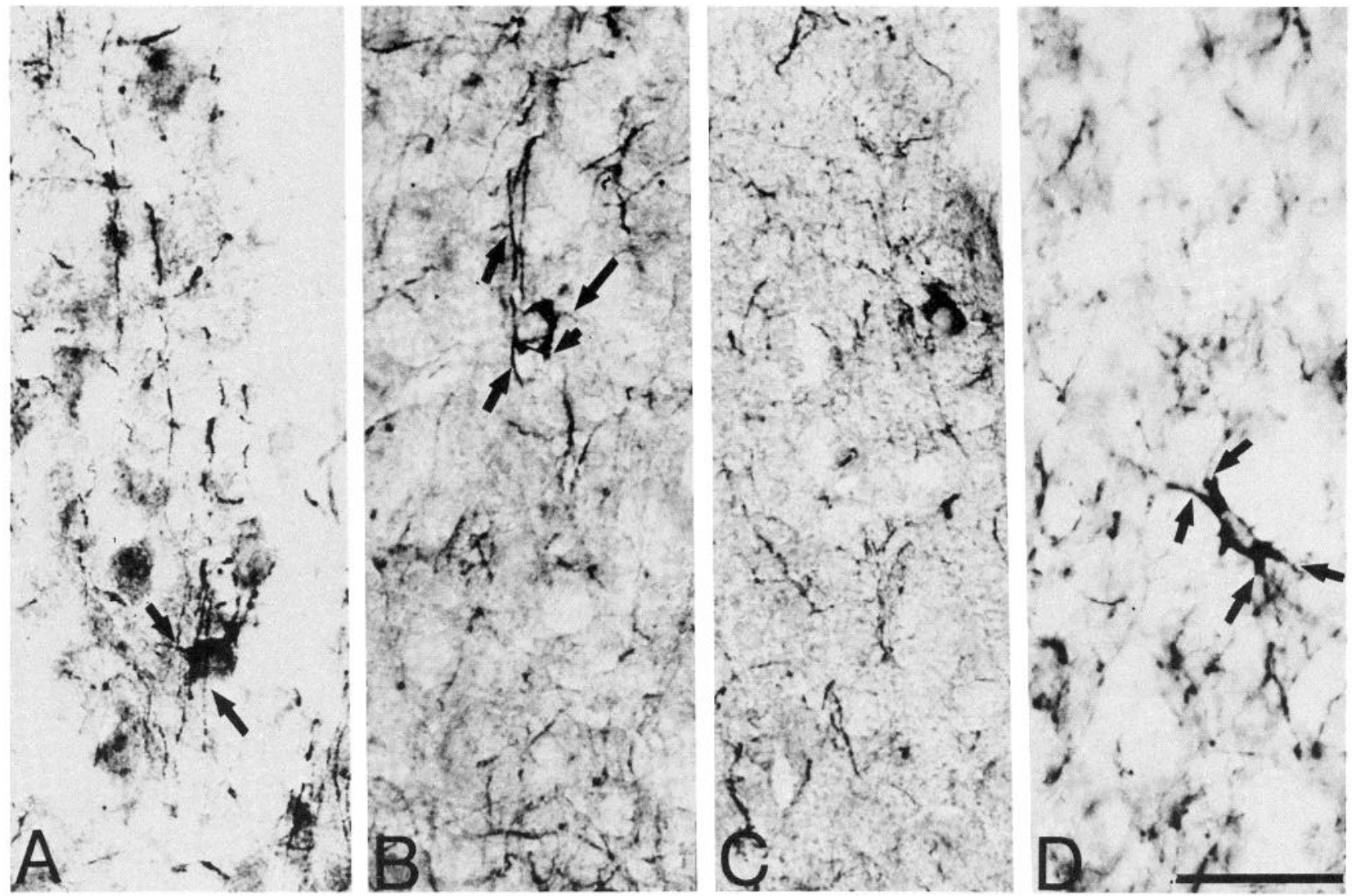

Figure 12. Higher power micrographs of typical, conventional immunoreactive perikarya with antisera against $\mathrm{P} 6$ in somatosensory cortex. $A$ and $B$ are from mid-layer III, $C$ is from layer V, and $D$ is within the subcortical white matter. In $A$, arrows indicate thick perikaryal processes; fine, varicose, radial fibers from another source are seen coursing across this reactive neuron. $\ln B$ and $D$, arrows indicate longer and shorter perikaryal processes traceable to these neurons. Calibration bar in $D=50 \mu$ (for $A$ to $D$ ). 


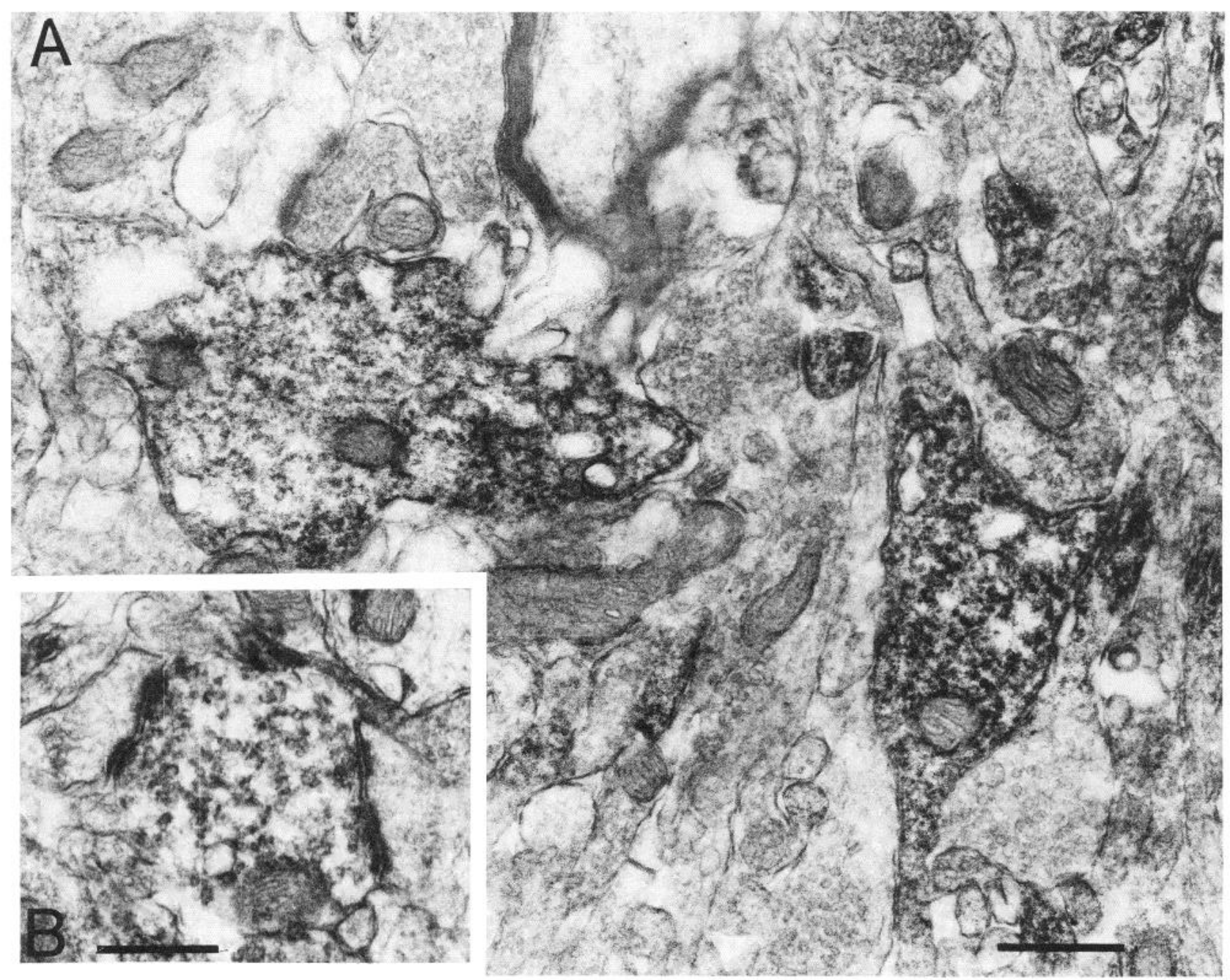

Figure 13. Electron microscopic localization of P5 immunoreactivity in layer III within probable dendritic structures $(A)$ and a nerve terminal $(B)$. In the latter, immunoprecipitates surround the synaptic vesicles. Calibration bars $=0.5 \mu \mathrm{m}$.

cortex, and in more scattered form within and the deep to the cerebral cortex. Such subcortical neurons have been seen with other immunocytochemical methods (Hendry et al., 1984b).

A less conventional, perikaryal structure also exhibited $1 \mathrm{~B} 236$ immunoreactivity in rats pretreated wirth colchicine, termed here as "hairy" cells for their apparent fine multiple perikaryal expansions. These cells were seen in areas that were otherwise intensely immunoreactive with neurite and fiber staining and, in several cases, were intermingled with conventional multipolar, large, immunoreactive neurons. Further studies will be required to determine whether this "hairy" appearance represents their unperturbed form or a toxic response to the colchicine pretreatment. Preliminary studies with the same series of antisera applied to early postnatal rodent brains and to adult primate brains suggest that the demonstration of immunoreactive perikarya there will not require colchicine for visualization.

Third, when animals were pretreated with colchicine to enhance perikaryal immunoreactivity, certain layer-specific zones of fiber-like processes were simultaneously diminished. This complementary enhancement/reduction was seen most prominently within the layer I fibers of the somatosensory cortex (Friedman, 1983), and the molecular layer fibers of the cerebellar cortex. Furthermore, immunoreactive structures, presumably axons, within myelinated tracts showed a thick straight course that follows known tracts (the intrastriatal striations, the lateral olfactory tract, and the fornix/fimbria) as well as a finer, more terminal-like structure surrounding presumptive terminal field structures. Fourth, preliminary and selected fields examined for electron microscopic immunoreactivity establish that regions with intense fiber-like staining exhibit this immunoreactivity in structures identifiable as synaptic vesicles within nerve terminals or boutons en passage.

Given this array of structural features, as well as the evidence from mRNA hybridization studies already reported that attribute the $1 \mathrm{~B} 236 \mathrm{mRNA}$ to neuronal and not glial sources (Sutcliffe et al., 1983), we conclude that 1B236 protein is expressed by a limited but extensive population of central neurons. However, it is not clear what the function of this protein is within these immunoreactive circuits, and what implications can be drawn from our interpretation of the selective nature of the systems it marks.

The peptides P5, P6, and P7 were initially selected as immunogens because these sequences were flanked in the primary 1B236 protein sequence by basic dipeptides that we considered to be possible proteolytic cleavage sites (Fig. 1). Ongoing studies aimed at defining the molecular forms of the 1B236 peptide (Malfroy et al., 1985) indicate that small peptides, similar in size to those selected for use as immunogens, and sharing immunoreactivity with them, may be formed by post-translational processing. Such evidence will be critical to validate the hypothesis (Sutcliffe et al., 1983) that the 1B236 protein is the precursor for a series of possible smaller messenger peptides. Until such issues can be firmly established, the observed ability of P5 and P6 to influence spontaneous or elicited activity of hippocampal or neocortical neurons (S. J. Henriksen, personal communication) and spontaneous locomotor behavior 


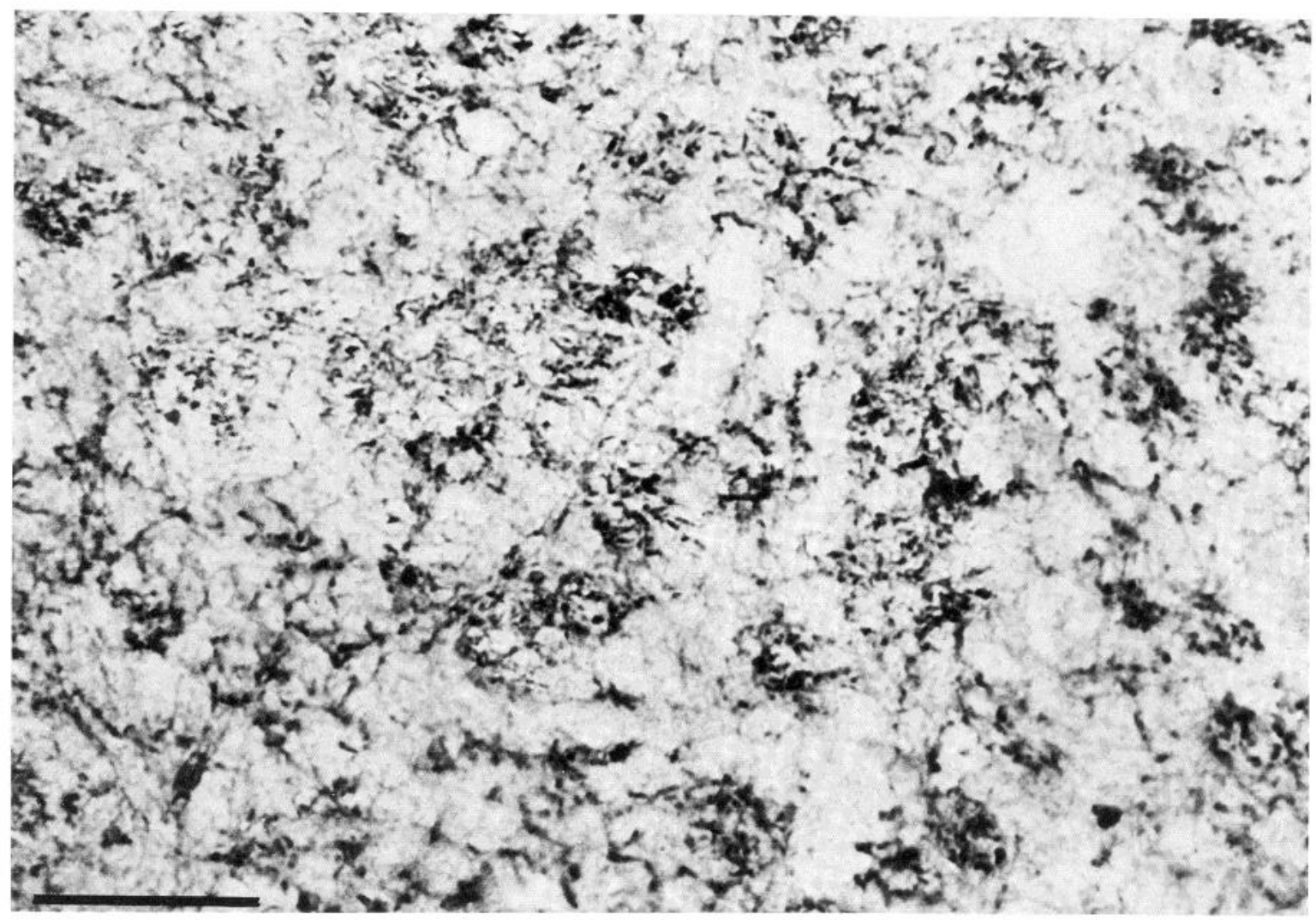

Figure 14. Dense neuropil within the lateral reticular nucleus of the thalamus, surrounding unstained neurons. Similar dense patterns were seen within the anterior ventral, ventroposterolateral, and ventrolateral nuclei, with more modest staining seen within the intralaminar nuclei. Calibration bar $=50 \mu \mathrm{m}$.

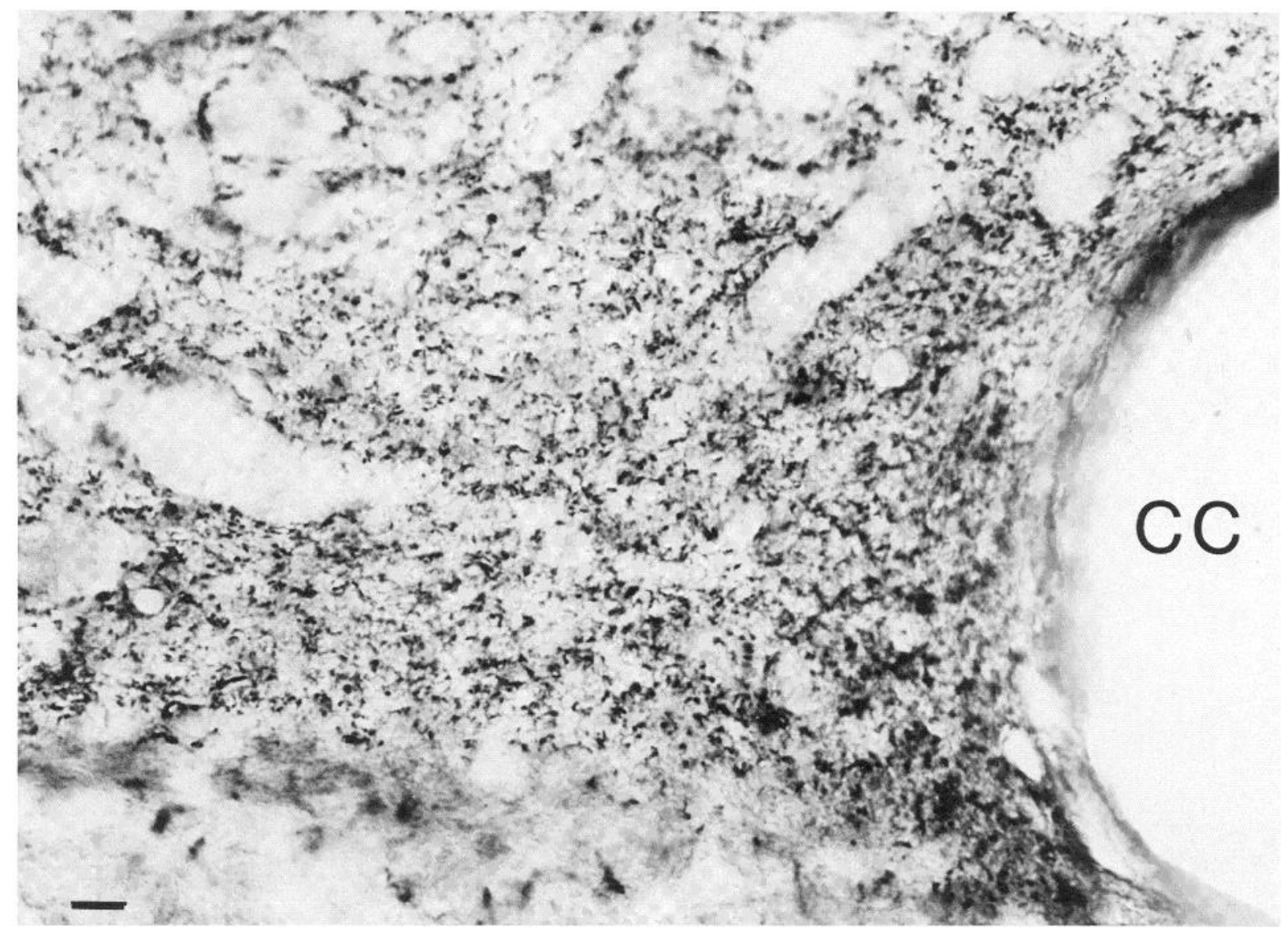

Figure 15. Dense perisomatic staining seen in the dorsal motor nucleus of the vagus is similar to that seen surrounding other cranial motor nuclei and contrasts with the minimal staining within the adjacent nucleus tractus solitarius above. The central canal $(C C)$ can be seen at far right. Calibration bar $=25$ $\mu \mathrm{m}$. 


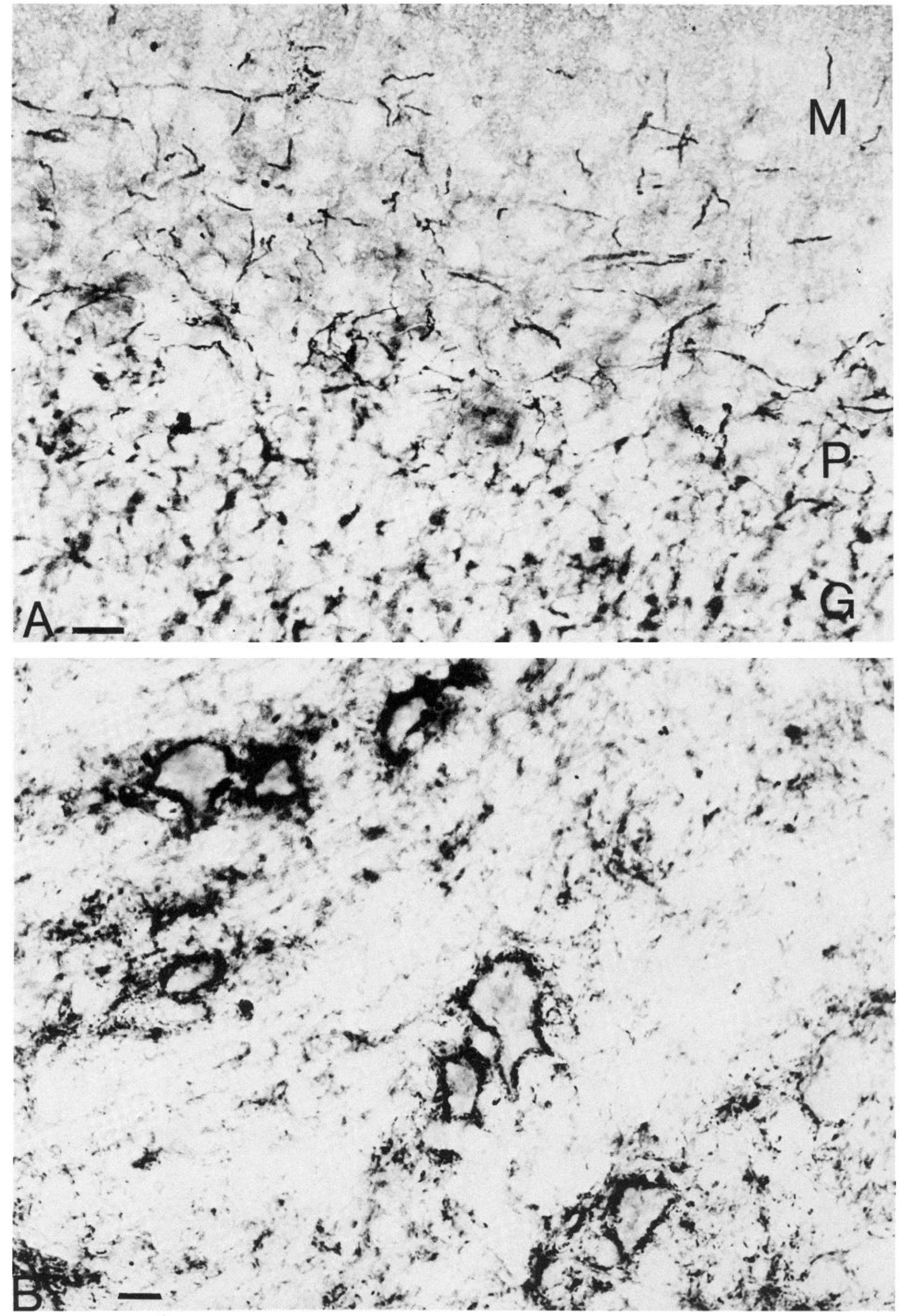

Figure 16. Immunoreactivity within the cerebellum. In $A$, dense fiber staining can be seen within the cerebellar cortex where thick, smooth branched processes are seen within the granule cell neuropil $(G)$, surrounding the Purkinje perikarya $(P)$, and coursing horizontally across the proximal molecular layer (M) just above the Purkinje cell layer. In $B$ can be seen the dense perisomatic immunoreactivity surrounding cells of the deep cerebellar nuclei, as illustrated in this typical view of the interpositus nucleus. Thick, large immunoreactive elements surround the perimeter of the unreactive neurons. This perisomatic immunoreactivity was seen with antisera against P5, but not with antisera against P6 or P7. Calibration bars $=25 \mu \mathrm{m}$. 


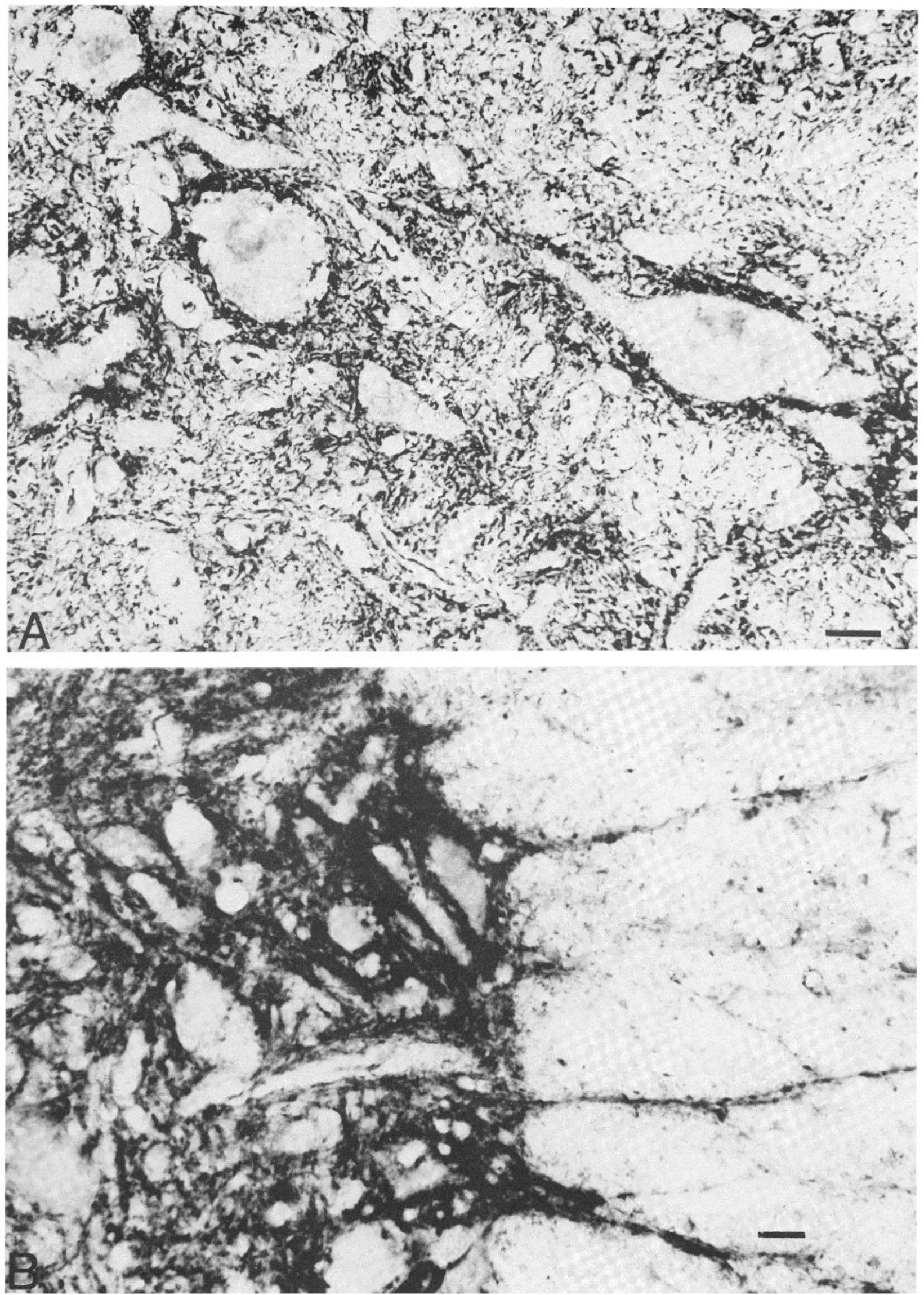

Figure 17. Immunoreactivity patterns in motor neuron fields. The dense clusters of punctate immunoreactive elements that surround the trigeminal motor neurons $(A)$ and the ventral horn cells $(B)$ can be seen. Calibration bars $=25 \mu \mathrm{m}$. 

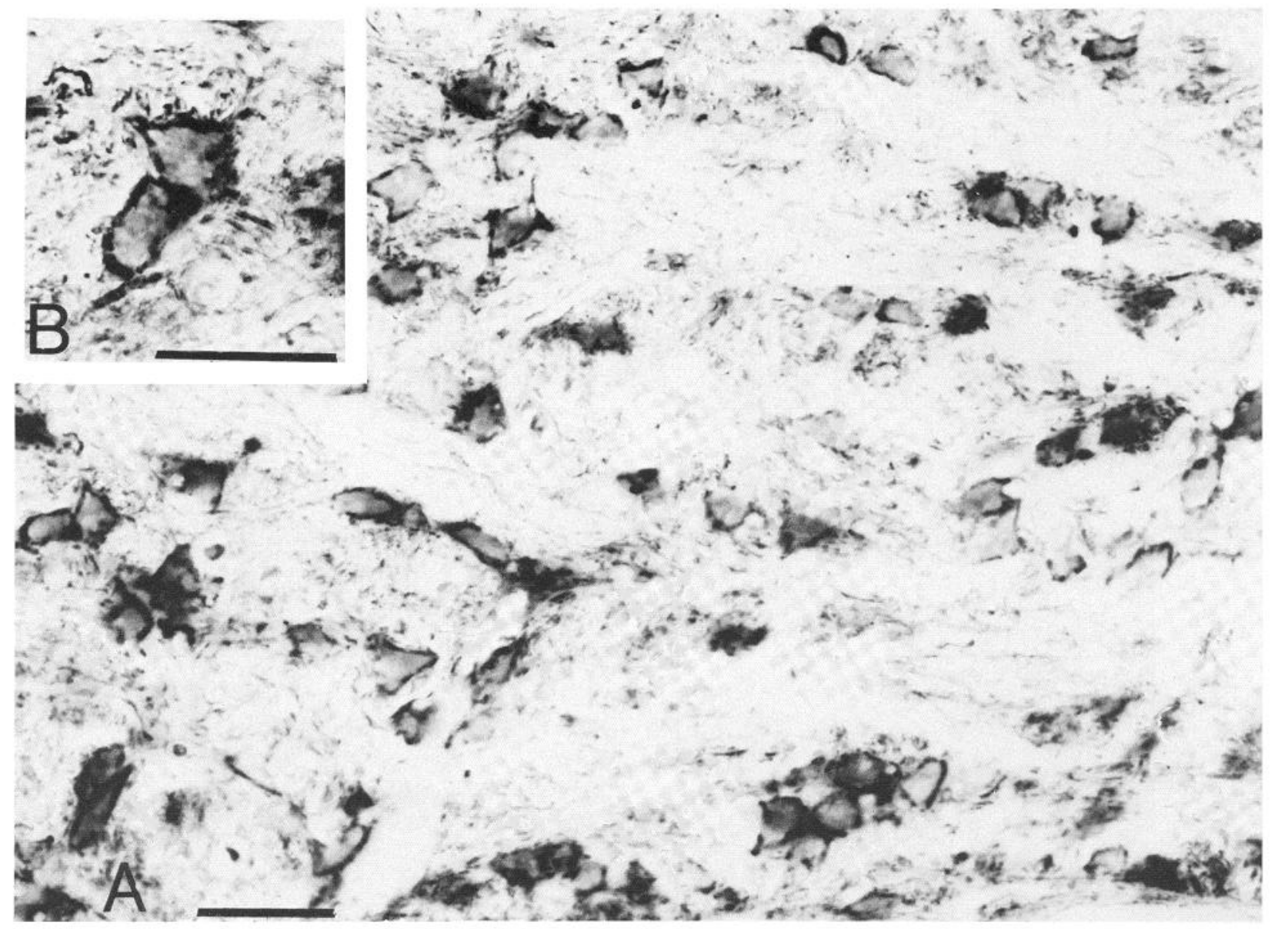

Figure 18. Antisera raised against P5 revealed granular reaction product with dense smooth outer rims in the external cytoplasmic perimeter of neurons of the medial trapezoid nucleus after colchicine exposure. This pattern can be seen more clearly at higher magnification (B). Antisera raised against P6 and P7 showed minimal staining of these neurons under identical conditions. Calibration bar $=25 \mu \mathrm{m}$.

\section{$1 B 236$ IMMUNOREACTIVE NEURONS}

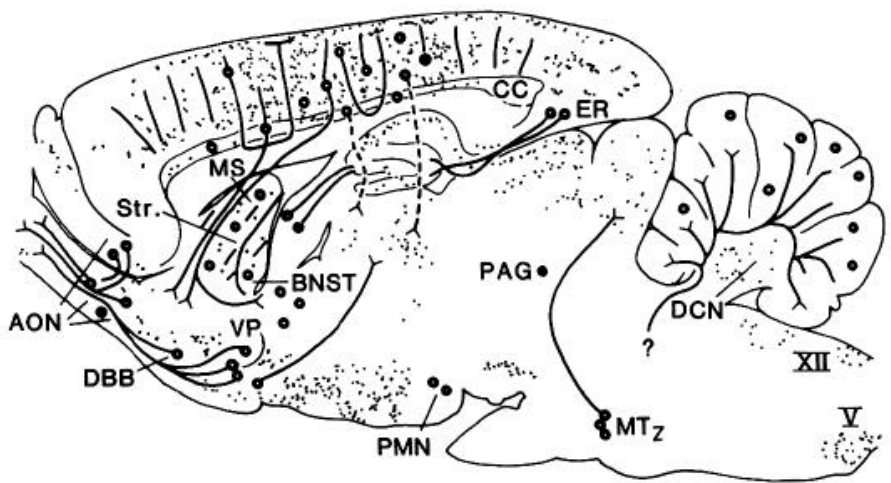

Figure 19. Schematic overview of neuropil and perikaryal immunoreactivity patterns. As indicated in Table I, an extensive, but virtually identical, pattern of immunoreactive fibers can be visualized throughout the normal rat CNS with antisera raised against $\mathrm{P} 5, \mathrm{P} 6$, or $\mathrm{P7}$. The immunoreactivity is especially dense in olfactory bulb and peduncle, specific hypothalamic and preoptic nuclei, the neostriatum, and limbic and neocortical regions. Neuropil staining was also prominent within selected thalamic and cranial nerve nuclei, as well as in cerebellum and spinal cord. Cell body-rich regions are symbolized by circles; neuropil-rich regions are shown by dots; presumptive fiber trajectories are symbolized by solid lines; and putative pathways are shown by dashed lines. The source of the immunoreactive fibers ending in the granule cell layer of the cerebellum is not yet known (?); the targets of the cells seen
(G. Koob, personal communication) can only be taken as suggesting a transmitter-like function. However, the generally superimposable cellular maps, the vesicular location, the predominance of P6 immunoreactivity in those neurons which do become visualizable after colchicine pretreatment, and the loss of terminal-like staining for all three peptides when cell body immunoreactivity is enhanced are consistent with the view that there is a large precursor form of the protein, which is processed during its transit through the perikaryal cytoplasm en route to nerve terminals.

With this hypothesis in mind, the exceptions to the generally superimposable maps of immunoreactive structures take on some added interest. Clearly, at this point, the most likely explanation for these rare exceptions (Table III) is that these structures contain a cross-reactive epitope of unknown structure and, thus, that these exceptions have no other biological importance. Alternative explanations, however, with a more substantive meaning, can be considered. Regions that exhibit immunoreactivity to P5, but not P6 or P7, such as the neurons of the medial trapezoid nucleus and the nerve terminal-like staining surrounding the neurons of the deep cerebellar nuclei, may represent partial differential processing, with no transla-

within the periaqueductal gray and the premammillary nuclei are also unspecifiable at this time. AON, anterior olfactory nuclei; BNST, bed nucleus of the stria terminalis; $C C$, corpus callosum; $D B B$, diagonal band of Broca; $D C N$, deep cerebellar nuclei; $E R$, entorhinal cortex; $M S$, medial septal nucleus: $M T_{z}$, medial trapezoid nucleus; $P A G$, periaqueductal gray; $P M N$, premammillary nucleus; Str., striatum; $V P$, ventral pallidal area; $V$, spinal trigeminal nucleus; XII, hypoglossal nucleus. 
tion or with post-translational proteolysis of the major immunogens of P6 and P7 in these structures. However, no simple alternative exists to explain the presence of P7 immunoreactivity in those structures not exhibiting reactivity with antisera to P5 or P6. Although this isolated finding within the magnocellular neurons probably represents only a cross-reacting endogenous epitope read by the P7 antisera, such a result would also be compatible with alternative RNA exon splicing for P7 without P5 or P6, analogous to the expression of mRNAs for the calcitonin gene-related peptide (Rosenfeld et al., 1983). There is some evidence that such mRNA processing alternatives may exist. Sequence analysis of the different forms is currently in progress and could help explain these apparent, but minor, inconsistencies in immunoreactivity detected by antisera against P5, P6, and P7. These exceptions serve well to illustrate the confidence level achievable when nonoverlapping synthetic fragments are used to generate immune reagents that give superimposable cytological patterns. When these conditions are met, the antisera can provide more information than can conventional immunocytochemistry or even monoclonal antibody-based cytochemistry, due to the convergence on the same protein by antisera against adjacent segments. Furthermore, because the present approach has demonstrated that an immunologically identical protein is expressed in different neurons, it is also possible to infer that these cells may share similar chemical properties and perhaps epigenetic states.

Regardless of whether $1 \mathrm{~B} 236$ protein represents a transmitter or some other class of cell-specific neuronal protein, the function of which remains to be determined, the distribution of this marker within functional circuits of the rat brain deserves further consideration. The 1B236 protein is clearly not expressed by every neuron within any of these systems, even those that are most heavily labeled. As one traces through the circuitry of the olfactory system (De Olmos et al., 1978; Haberly and Price, 1978; Price and Slotnick, 1983; Shepherd, 1983), it is clear that the primary olfactory nerves, as well as the primary output cells of the bulb-the mitral cells-are both unreactive. However, some periglomerular cells, some short-axon cells of the internal plexiform layer, and some large neurons within almost all regions directly innervated by the lateral olfactory tract, and known to send centrifugal fibers back to the granule cells of the bulb (see Shephard, 1983), are all strongly positive. Furthermore, afferents to the mediodorsal thalamus (Vogt et al., 1981; Price and Slotnick, 1983), to the piriform and olfactory regions of the forebrain (Krettek and Price, 1977a, b), and those for which the source locations are not yet determined are also strongly positive. Somatosensory and amygdaloid neurons with immunoreactivity for 1B236 could account for these circuits (Shipley and Geinisman, 1984).

Within the olfactory structures, the immunoreactive elements alternate with nonimmunoreactive elements in the multisynaptic chains of interconnected neurons that have been well studied for these functional systems (Fig. 20). The meaning of such an alternating pattern of expression of a specific marker is not obvious. At one level, it can be directly interpreted as reflecting only that these cells contain the same protein and hence share at least one specific chemical property which may relate these separated cell types functionally. It is possible that expression of the 1B236 mRNA and its protein product also reflects some primary epigenetic property shared by neurons in each of these systems as well as by the cells of functionally separate systems. Such concepts are ultimately testable by developmental (D. Lenoir, E. Battenberg, F. E. Bloom, J. G. Sutcliffe, and R. J. Milner, manuscript in preparation) and phylogenetic studies. The data presently at hand favor the possibility that the $1 \mathrm{~B} 236$ protein could function as a neurotransmitter precursor within those circuits that express it, although the evidence is far from complete.

Similarly, there also may be patterns to the immunoreactive cell bodies and neuropil target fields identified within limbic structures: the fornix projection from the medial septum is strikingly positive, as is the perforant path input to the outer molecular layer of the dentate gyrus, and the possible amygdaloid inputs (Krettek and Price, 1977a, b) to the ventral and dorsal subiculum. However, within the hippocampal formation proper, there are no positive perikarya detectable and there are no obvious immunoreactive neuropil-like elements

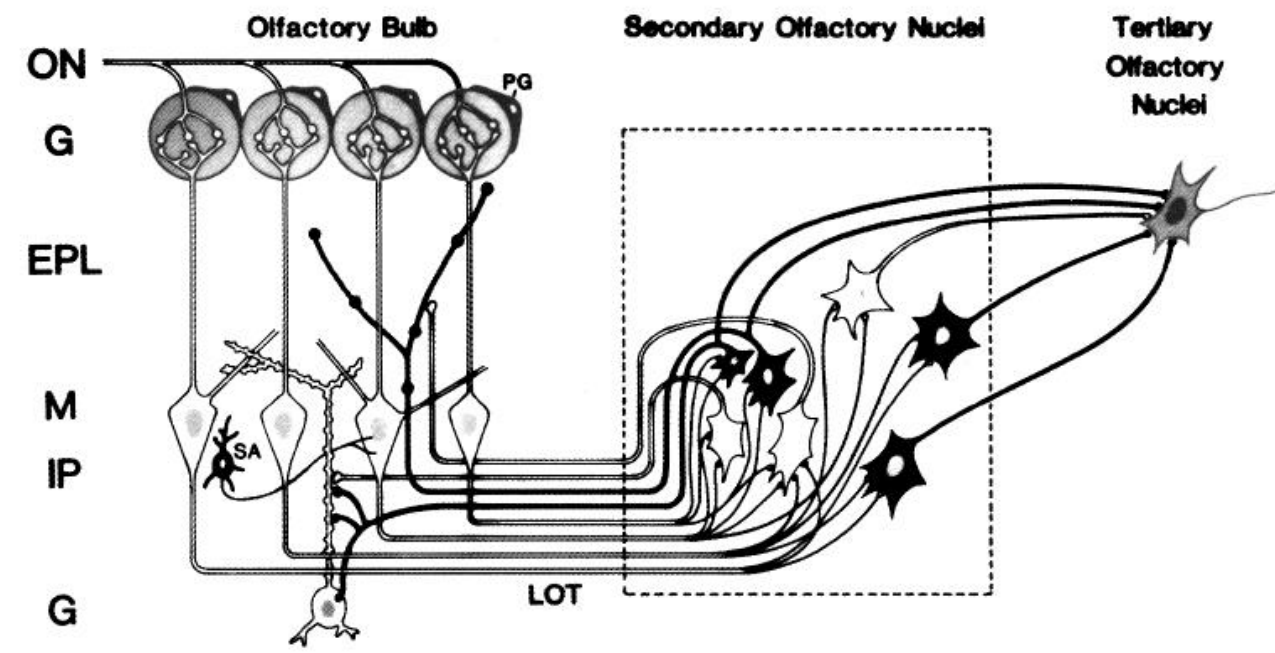

Figure 20. Schematic representation of the pattern of $1 \mathrm{~B} 236$ immunoreactivity for P5, P6, and P7 within the olfactory bulb. Immunoreactive cells are represented within the bulb by the periglomerular $(P G)$ neurons within the glomerular layer $(G)$, and by the short-axon (SA) neurons within the internal plexiform layer (IP). Intense immunoreactivity is also seen within the internal plexiform layer and in thick straight processes which occasionally course across the external plexiform layer (EPL). Centrifugal fibers are known to enter the bulb through the lateral olfactory tract (LOT), to innervate olfactory granule cells $(G)$, and to arise from the secondary olfactory nuclei, where a small but significant fraction of the perikarya are immunoreactive. These regions include the accessory olfactory nuclei, the medial cortical amygdala, the diagonal band, the endopiriform nucleus, and the primary olfactory cortex. In addition, several of these immunoreactive neurons in the secondary olfactory target areas also send immunoreactive neuropil to the medial dorsal thalamic nucleus. The distribution of 1B236 peptide immunoreactivity within the olfactory system is extensive, with immunoreactive elements positioned at the interface of the hierarchical afferent links: across the glomeruli where immunoreactive periglomerular neurons span the synapses between the nonimmunoreactive olfactory nerve fibers and the nonimmunoreactive mitral $(M)$ and tufted neurons, and at the internal plexiform layer, where the short-axon cells and the centrifugal afferents may regulate the flow of information between the nonimmunoreactive mitral and granule cells. One interpretation of this pattern of immunoreactive elements is that it may represent a distributed, interrupted system for the regulation of olfactory information processing. 
suggestive of intrahippocampal associational fibers. Within neocortex, the present evidence would be compatible with the view that intracortical association fibers, as well as corticothalamic and possibly other cortical efferents, express 1B236. Undercutting experiments are in progress to evaluate this possibility. The undetectable staining within the medial frontal cortex, as well as its absence from a major target field, the nucleus tractus solitarius (Terreberry and Neafsey, 1983; Van der Kooy et al., 1984), and from most of the visual system, hypothalamus, midbrain, and reticular formation, attests to the possible significance of the expression of 1B236 in those cells and systems that do share it. Clearly, however, assumptions about connectivity based only on immunocytochemical reactivity in cells and neuropil are inadequate to establish the functional circuitry we propose as containing $1 \mathrm{~B} 236$ protein

In any case, the present studies provide two major pieces of strategic information regardless of the ultimate significance of the precise location and function of this specific marker. First, immunoassay based upon antisera raised against synthetic peptides for which the sequences are deduced from the nucleic acids of their mRNA is an effective way to establish novel markers of discrete cell classes within the brain, independent of any a priori assumptions about the nature of such marker molecules. Clearly, such antisera are suitable for immune localization of specific proteins. Second, the use of immunocytochemistry provides a strong basis for initial functional concepts based upon the patterns of regional immunoreactivity and the details of intracellular morphology. In our view, these findings suggest that a strategy of molecular discovery based upon the expression of select groups of mRNAs in brain can provide an effective and conceptually unconstrained approach to the further specification of a more complete list of the molecular properties that uniquely characterize the brain.

\section{References}

Bantle, J. A., and W. E. Hahn (1976) Complexity and characterization of polyadenylated RNS in the mouse brain. Cell 8: 139-150.

Barnstable, C. J. (1980) Monoclonal antibodies which recognize different cell types in the rat brain. Nature 286: 231-235.

Bloom, F. E., and E. L. F. Battenberg (1983) Immunocytochemistry of endorphins and enkephalıns. Methods Enzymol. 103: 670-687.

Bloom, F. E., T. Ueda, E. Battenberg, and P. Greengard (1979) Immunocytochemical localization in synapses of protein I, an endogenous substrate for protein kinases in mammalian brain. Proc. Natl. Acad. Sci. U. S. A. 76. 5982-5986.

Chikaraishi, D. M. (1979) Complexity of cytoplasmic polyadenylated and nonpolyadenylated rat brain ribonucleic acids. Biochemistry 18: 3249 3256.

Cohen, J., and S. Y. Selvendran (1981) A neuronal cell-surface antigen is found in the CNS but not in peripheral neurones. Nature 291: 421-423.

De Olmos, J., H. Hardy, and L. Heimer (1978) The afferent connections of the main and the accessory olfactory bulb formations in the rat: An experimental HRP-study. J. Comp. Neurol. 181: 213-244.

Eng, L. F. (1982) The glial fibrillary acidic protein: The major protein constituent of glial filaments. Scand. J. Immunol. 9: 41-51.

Friedman, D. P. (1983) Laminar patterns of termination of cortico-cortical afferents in the somatosensory cortex. Brain Res. 273: 147-151.

Haberly, L. B., and J. L. Price (1978) Association and commissural fiber systems of the olfactory cortex of the rat. J. Comp. Neurol. 178: 711-740.

Hendry, S. H. C., S. Hockfield, E. G. Jones, and R. McKay (1984a) Monoclonal antibody that identifies subsets of neurons in the central visual system of monkey and cat. Nature 307: 267-269.

Hendry, S. H. C., E. G. Jones, and P. C. Emson (1984b) Morphology, distribution, and synaptic relations of somatostatin- and neuropeptide $Y$. immunoreactive neurons in rat and monkey neocortex. J. Neurosci. 4: 2497-2517.

Kennedy, P. G. (1982) Neural cell markers and their applications to neurology. J. Neuroimmunol. 2: 35-53.

Krellek, J. E., and J. L. Price (1977a) Connections Irom the arnygdaloid complex to the cerebral cortex and thalamus in the rat and cat. J. Comp. Neurol. 172: 687-722.

Krettek, J. E., and J. L. Price (1977b) Projections trom the amygdaloid complex and adjacent olfactory structures to the entorhinal cortex and subiculum, in the rat and cat. J. Comp. Neurol. 172: 723-752.

Krieg, W. J. S. (1946) Connections of the cerebral cortex. I. The albino rat: A topography of the cortical areas. J. Comp. Neurol. 84: 221-275.

Krieg, W. J. S. (1948) The medial region of the thalamus of the albino rat. J. Comp. Neurol. 90: 381-417.

Levitt, P. (1984) A monoclonal antibody to limbic system neurons. Science 233: 299-301.

Luskin, M. B., and J. L. Price (1983) The topographic organization of associational fibers of the olfactory system in the rat, including centrifugal fibers to the olfactory bulb. J. Comp. Neurol. 216: 264-291.

Malfroy, B., C. Bakhit, F. E. Bloom, J. G. Sutcliffe, and R. J. Milner (1985) The brain specific polypeptide 1B236 exists in multiple molecular forms. Proc. Natl. Acad. Sci. U. S. A., in press.

McKay, R., M. C. Raff, and L. F. Rerchardt (1981) Monoclonal antibodies to neuronal antigens. Cold spring Harbor Rep. Neurosci. 2: 1-282.

Milner, R. M., and J. G. Sutcliffe (1983) Gene expression in rat brain. Nucleic Acids Res. 11: 5497-5520

Moore, B. W. (1982) Chemistry and biology of the S-100 protein. Scand. J. Immunol. 9: 53-74.

Palay, S. L., and V. Chan-Palay (1974) Cerebellar Cortex: Cytology and Organization, Springr-Verlag, New York.

Paxinos, G., and C. Watson (1982) The Rat Brain in Stereotaxic Coordinates, Academic Press, inc., New York.

Price, J. L., and B. M. Slotnick (1983) Dual olfactory representation in the rat thalamus: An anatomical and electrophysiological study. J. Comp. Neurol. 215: 63-77.

Richardson, K. D., L. Jarrett, and E. H. Finke (1960) Embedding in epoxy resins for ultrathin sectioning in electron microscopy. Stain Technol. 35: 313-323.

Rosenteld, M. G., J. -J. Mermod, S. G. Amara, L. W. Swanson, P. E. Sawchenko, J. Rivier, W. W. Vale, and R. M. Evans (1983) Production of a novel neuropeptide encoded by the calcitonin gene via tissue-specific RNA processing. Nature 304: 129-135.

Schachner, M. (1982) Cell type-specific surface antigens in the mammalian nervous system. J. Neurochem. 39: 1-8.

Schmechel, D., P. J. Marangos, and M. Brightman (1978) Neurone specific enolase is a marker for peripheral and central neuroendocrine cells. Nature 276: 831-836.

Shephard, G. M. (1983) Neurobiology, Oxford University Press, New York.

Shipley, M. T., and Y. Geinisman (1984) Anatomical evidence for convergence of olfactory, gustatory, and visceral afferent pathways in the mouse cerebral cortex. Brain Res. Bull. 12: 221-226.

Sternberger, L. A., L. W. Harwell, and N. H. Sternberger (1982) Neurotypy: Regional individuality in rat brain detected by immunocytochemistry with monoclonal antibodies. Proc. Natl. Acad. Sci. U. S. A. 79: 1326-1330.

Sutcliffe, J. G., R. J. Miiner, T. M. Shinnick, and F. E. Bloom (1983) Identifying the protein products of brain-specific genes with antibodies to chemically synthesized peptides. Cell 33: 671-682.

Terreberry, R. R., and E. J. Neafsey (1983) Rat medial frontal cortex: A visceral motor region with a direct projection to the solitary nucleus. Brain Res. 278: 245-249.

Thompson, R. J., J. F. Doran, P. Jackson, A. P. Dhillon, and J. Rode (1983) PGP 9.5 - a new marker for vertebrate neurons and neuroendocrine cells. Brain Res. 278: 224-228.

Van der Kooy, D., L. Y. Koda, J. F. McGinty, C. R. Gerfen, and F. E. Bloom (1984) The organization of projections from the cortex, amygdala and hypothalamus to the nucleus of the solitary tract in rat. J. Comp. Neurol. 224: $1-24$.

Villiamy, T., S. Rattray, and R. Mirsky (1981) Cell-surface antigen distinguishes sensory and autonomic peripheral neurons from central neurones. Nature 291: 418-420.

Vogt, B. A., and A. Peters (1981) Form and distribution of neurons in rat cingulate cortex: Areas 32, 24, and 29. J. Comp. Neurol. 195: 603-625.

Vogt, B. A., D. L. Rosene, and A. Peters (1981) Synaptic termination of thalamic and callosal afferents in cingulate cortex of the rat. J. Comp. Neurol. 201: 265-283.

Welker, C., and T. A. Woolsey (1975) Structure of layer IV in the somatosensory neocortex of the rat: Description and comparisons with the mouse. J. Comp. Neurol. 158: 437454.

Wise, S. P., and E. G. Jones (1977) Somatotopic and columnar organization in the corticotectal projection of the rat somatic sensory cortex. Brain Res. 133: 223-235

Wise, S. P., E. A. Murray, and J. D. Coulter (1979) Somatotopic organization of corticospinal and corticotrigeminal neurons in the rat. Neuroscience 4: $65-78$. 